Old Dominion University

ODU Digital Commons

Educational Foundations \& Leadership Theses

$\&$ Dissertations

Educational Foundations \& Leadership

Summer 8-2020

\title{
The Impact of Moderate Physical Activity and Student Interaction on Retention at a Community College
}

Anne Leavy-Prial

Old Dominion University, anne.prial@sunyorange.edu

Follow this and additional works at: https://digitalcommons.odu.edu/efl_etds

Part of the Community College Education Administration Commons, and the Higher Education Commons

\section{Recommended Citation}

Leavy-Prial, Anne. "The Impact of Moderate Physical Activity and Student Interaction on Retention at a Community College" (2020). Doctor of Philosophy (PhD), Dissertation, Educational Foundations \& Leadership, Old Dominion University, DOI: 10.25777/8fha-4924

https://digitalcommons.odu.edu/efl_etds/234

This Dissertation is brought to you for free and open access by the Educational Foundations \& Leadership at ODU Digital Commons. It has been accepted for inclusion in Educational Foundations \& Leadership Theses \& Dissertations by an authorized administrator of ODU Digital Commons. For more information, please contact digitalcommons@odu.edu. 


\author{
by \\ Anne Leavy-Prial \\ B.S. May 1985, Manhattan College \\ M.A. May 1988, Hofstra University \\ A Dissertation Submitted to the Faculty of \\ Old Dominion University in Partial Fulfillment of the \\ Requirements for the Degree of \\ DOCTOR OF PHILOSOPHY \\ COMMUNITY COLLEGE LEADERSHIP \\ OLD DOMINION UNIVERSITY \\ August 2020
}

Approved by:

Mitchell R. Williams (Director)

Linda Bol (Member)

Xihe Zhu (Member) 


\begin{abstract}
The Impact of Moderate Physical Activity and Student Interaction on Retention at a Community College
\end{abstract}

Anne Leavy-Prial

Old Dominion University, 2020

Director: Mitchell Williams

Student retention and persistence are key to student success. Therefore, it is of great concern to community college leaders that their students are retained. In addition to having the best interest of students in mind, community college leaders feel the pressure of performancebased funding to produce increased retention and graduation rates. Over the past several years, retention rates at community colleges in the United States have hovered below $50 \%$ (National Student Clearinghouse, 2019). The researcher of the current study implemented a very low-cost initiative with the intent of increasing retention at a community college.

The purpose of this study was to explore the effect of a voluntary walking program that combined moderate physical activity, student interaction with peers, and student interaction with college faculty, staff, and administrators, on student retention at a community college. For the current study, a sample of 69 students at a suburban community college voluntarily joined a walking program and logged the number of minutes they walked and the number of people they spoke to each day. The data were collected via Google sheets, individually shared only with the researcher. Using a Chi-Squared Test of Independence, the study sample was compared to a matched sample of students not in the walking program. It was found that there was a significant difference in these groups relative to retention. A Fisher's Exact Test was used to consider (a) the difference between participants who walked at least 150 minutes per week, as recommended by the American Heart Association (2018) and those who did not relative to retention and (b) the difference between participants who spoke to others while walking and those who did not 
relative to retention. These tests showed no significant differences. Community college leaders can use these findings to implement a low-cost approach to address the issue of student retention.

Keywords: retention, community college, moderate physical activity, sense of belonging, student interaction 
Copyright, 2020, by Anne Leavy-Prial, All Rights Reserved. 
This dissertation is dedicated to my dad, who instilled in me the passion for and understanding of the power of physical exercise; to my mom who encouraged me in all my endeavors, and to my husband, Greg, for all he sacrificed and did for me over these past five years. 


\section{ACKNOWLEDGEMENTS}

I wish to express my thanks first to faculty in the Community College Leadership program at Old Dominion University. They are dedicated and passionate about educating future leaders in community colleges. My sincere thanks to my chair, Dr. Mitchell Williams, who was instrumental in bringing me to the CCL program at ODU, and whose knowledge and guidance were invaluable to me. Thank you, also, to Drs. Bol and Zhu, for their time and direction as they brought me through the dissertation process. Dawn Hall, thank you for all the behind-the-scenes work you have done for me. Cohort 15, you have become my second family; thank you for being the much-needed support system and providers of comic relief! Thank you, Steve, for patiently answering the endless questions related to Excel, formatting, and anything computer related.

Thank you, Mom and Dad for my fairytale childhood and all the sacrifices you made for our family. Thank you to my husband, Greg, for taking on all the responsibilities of both of us for the past five years. To my children Becky, Terence, Danny, Brigid, and Jennie; and grandchildren Sam and Ada - thanks for understanding my absences at events that occurred during class, homework, or writing times. I look forward to spending more time with each of you and I love you all! 
TABLE OF CONTENTS

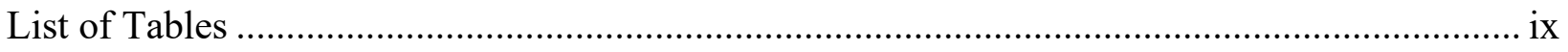

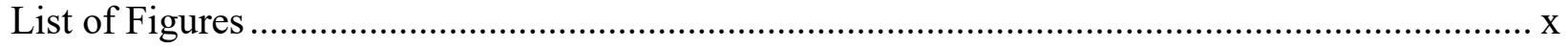

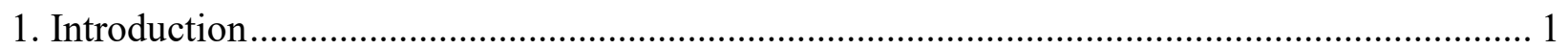

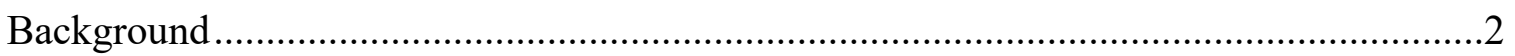

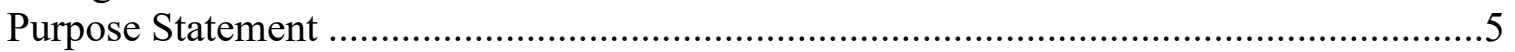

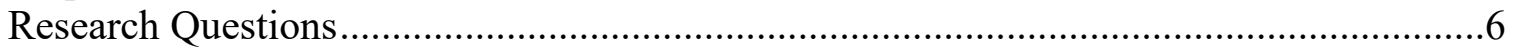

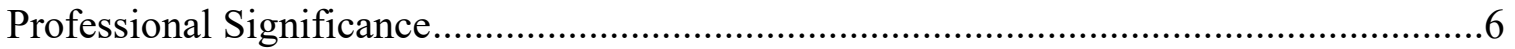

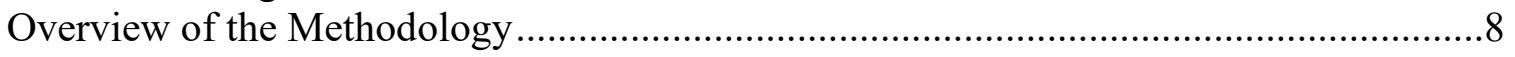

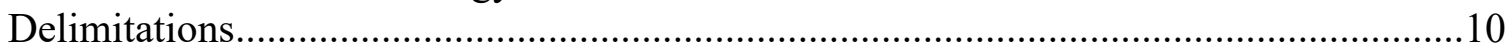

Operational Definitions …………………....................................................................

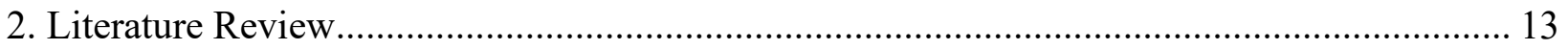

Purpose Statement ……………………………………....................................13

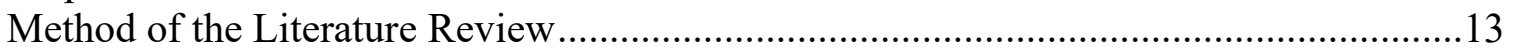

Theoretical and Conceptual Frameworks …………….................................................14

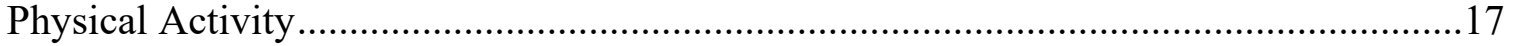

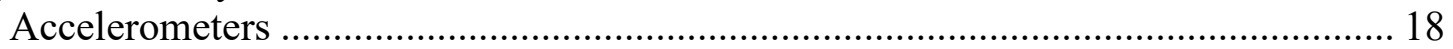

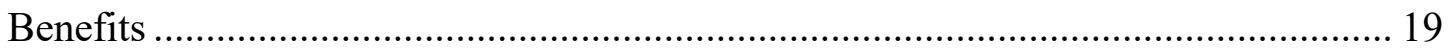

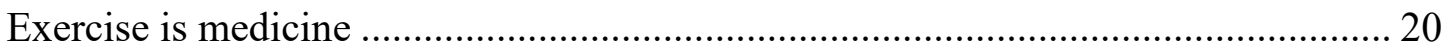

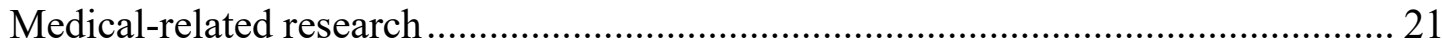

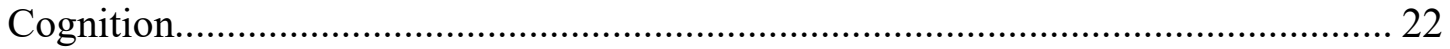

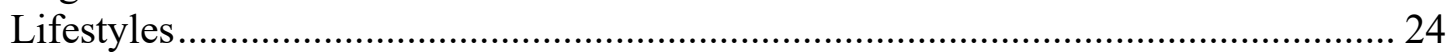

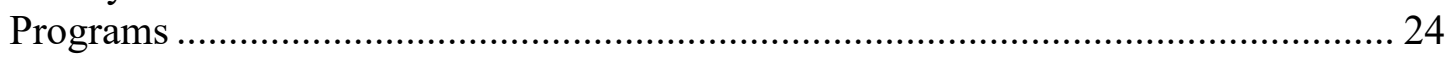

Exercise among community college populations ……………………………….... 26

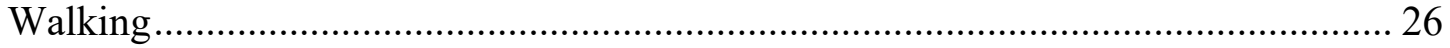

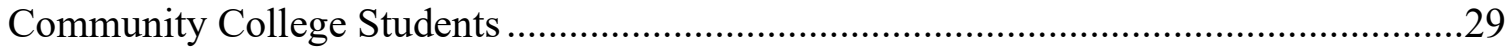

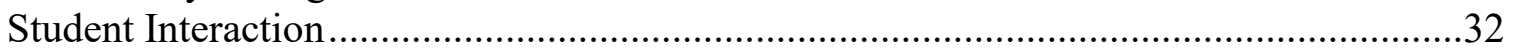

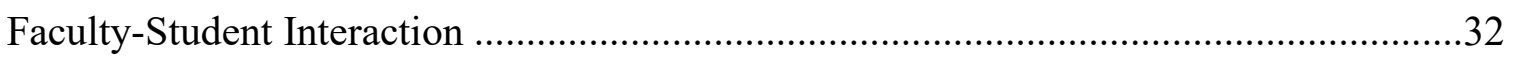

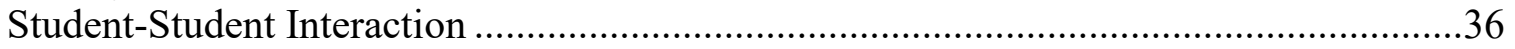

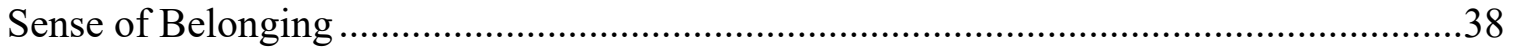

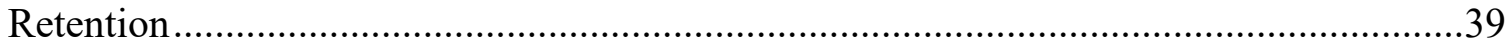

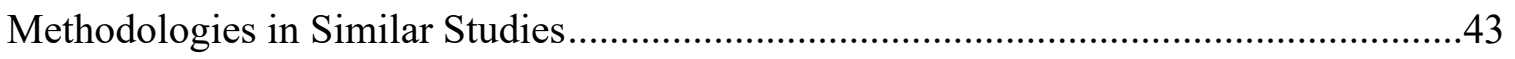

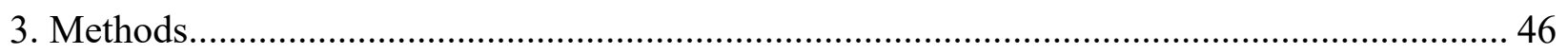

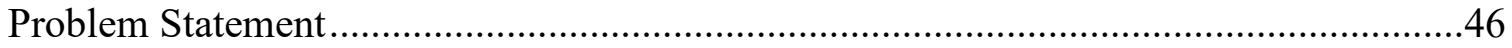

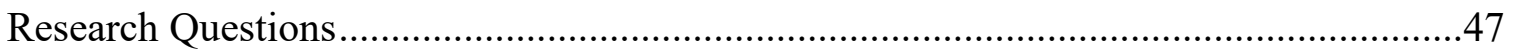

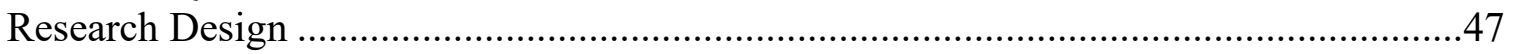

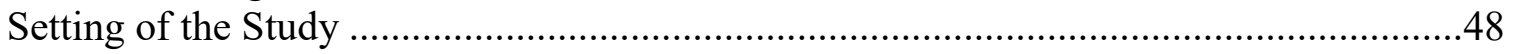

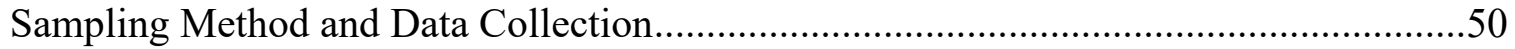

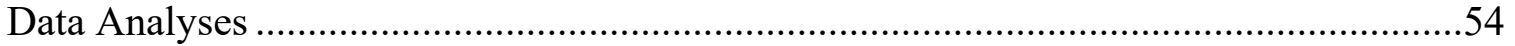




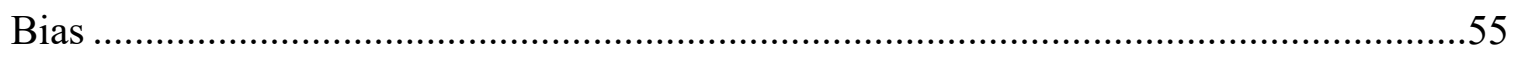

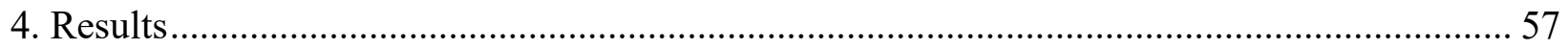

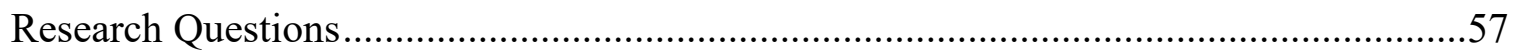

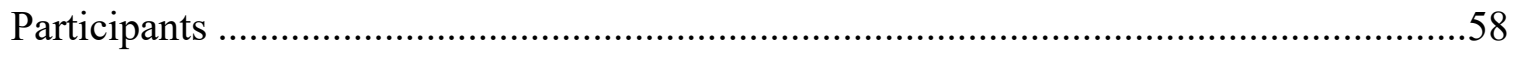

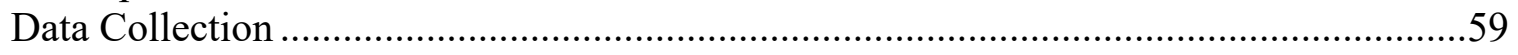

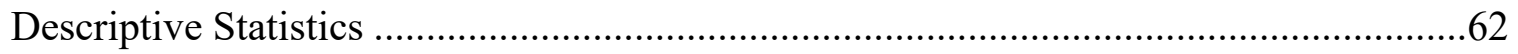

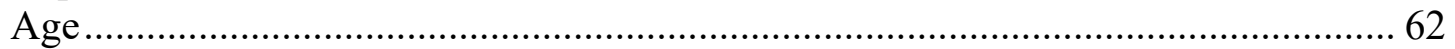

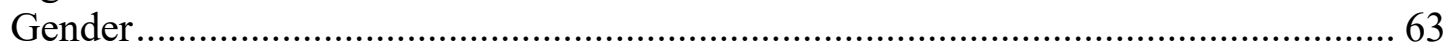

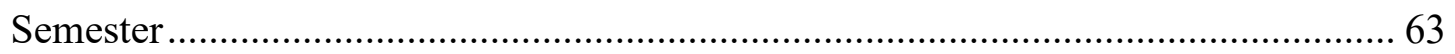

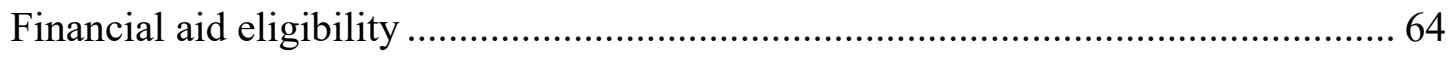

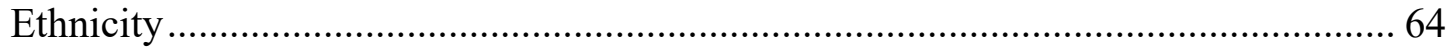

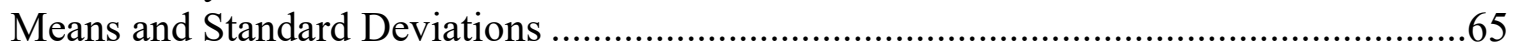

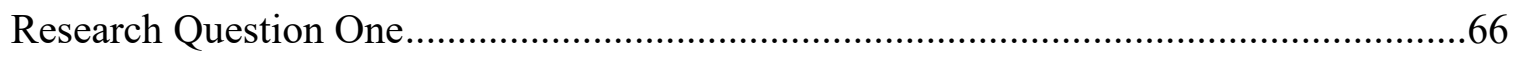

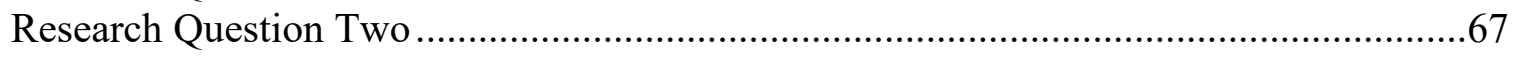

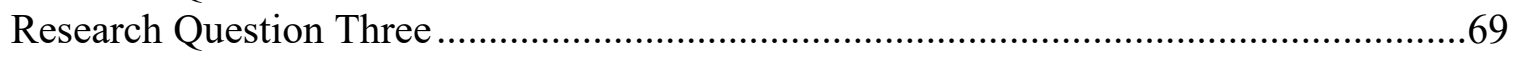

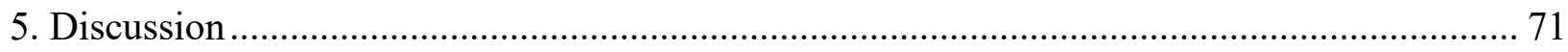

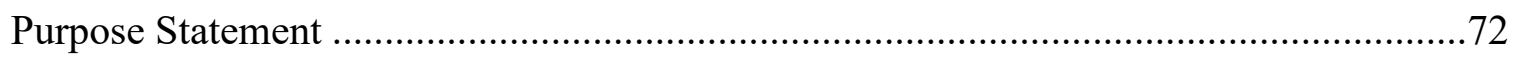

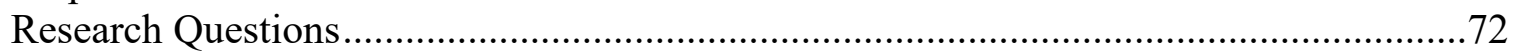

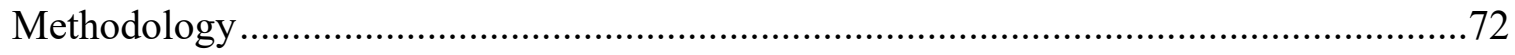

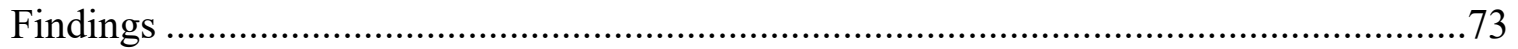

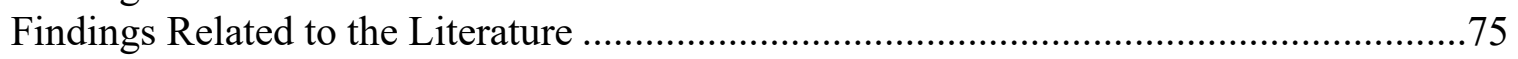

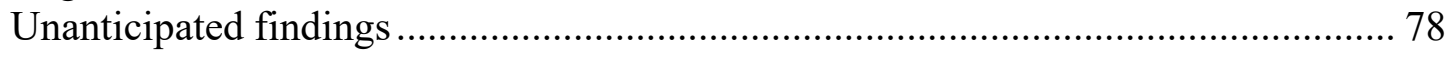

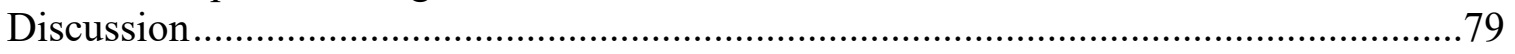

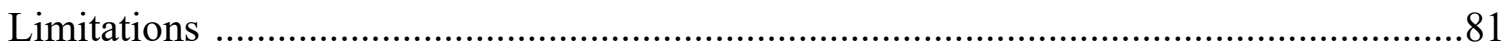

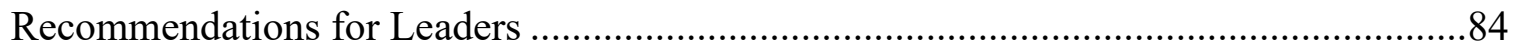

Recommendations for Future Research .............................................................. 88

Concluding Remarks.................................................... 89

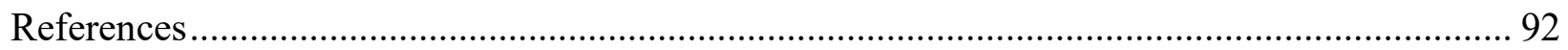

Appendices

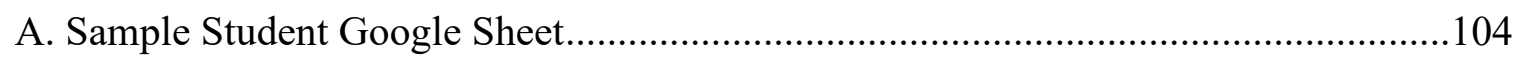

B. Sample Non-Student Google Sheet......................................................................105

C. Summary of Data of Student Walkers / Summary of Data from Matched Sample....106

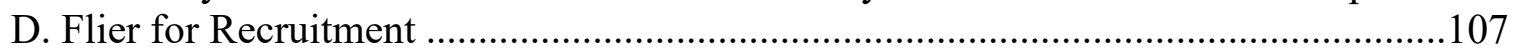

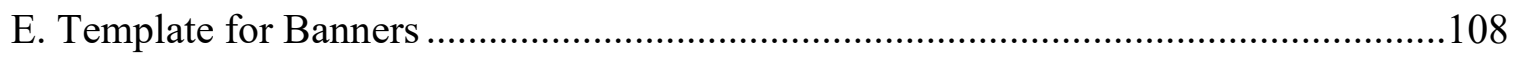

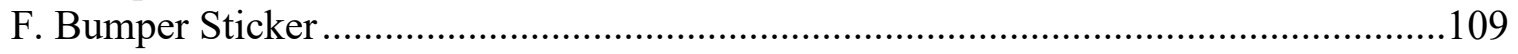

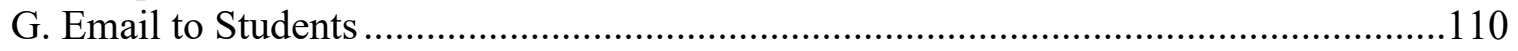


H. Old Dominion University Human Subject Approval Letter .

I. Suburban Community College Human Subject Approval Letter.................................112

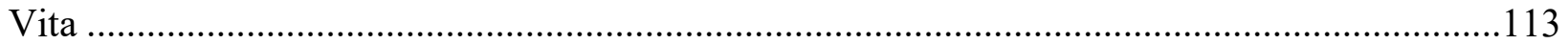




\section{LIST OF TABLES}

Table Page

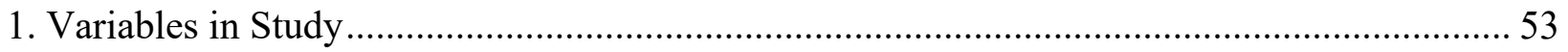

2. Frequency Distribution of Number of Days Walked .................................................... 60

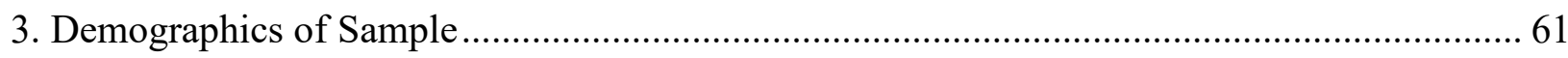

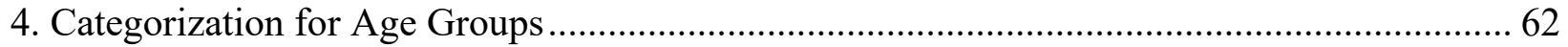

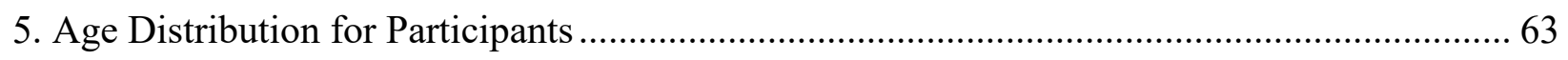

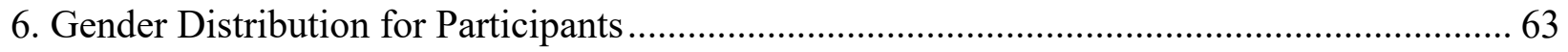

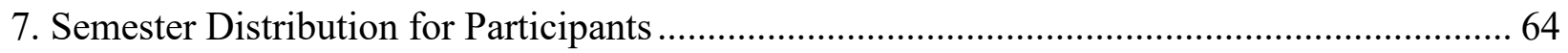

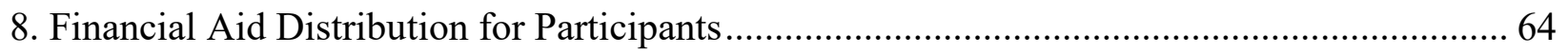

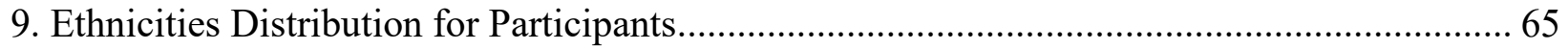

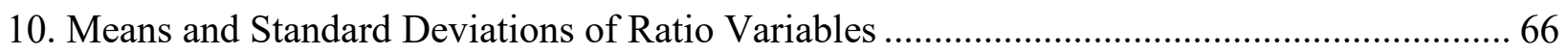

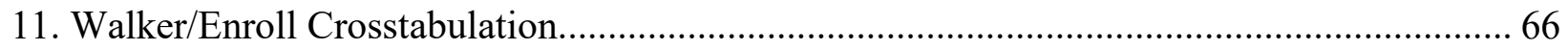

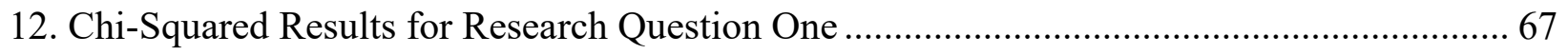

13. Number of Minutes per Day Walked / Enroll Crosstabulation.......................................... 68

14. Chi-Squared Results for Research Question Two: NMW ............................................... 69

15. NPS / Enroll Crosstabulation ....................................................................................... 70

16. Chi-Squared Results for Research Question Three: NPS …........................................... 70 


\section{LIST OF FIGURES}

$\begin{array}{lll}\text { Figure Page } & \text { Pan }\end{array}$

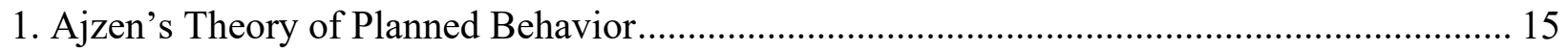

2. Tinto's Longinitudinal Model of Institutional Departure ………............................................ 16

3. Conceptual Framework for the Current Study ...................................................................... 17

4. Conceptual Framework for the Current Study with Sources .................................................... 41 


\section{CHAPTER 1}

\section{Introduction}

Student persistence and retention are of great concern to community college leaders. Since open access is fundamental to the mission of community colleges, it is important to stakeholders of these institutions to provide the opportunity for all interested students to earn a credential, which requires them to stay in college until graduation (McPhail, 2011). In 2009, President Barack Obama presented the nation with the Completion Agenda: he challenged the country to regain the number one ranking in the world for proportion of college graduates by 2020 (The White House, 2009). Since that time, community college leaders have felt the pressure of producing metrics that illustrate increasing persistence, retention, and completion. Tied to this pressure is performance-based funding, which relies on these metrics in decisions concerning distribution of monetary awards (McKinney \& Hagedorn, 2017; Romano \& Palmer, 2016).

Data from all years between and including 2009 and 2017 show that the percentage of students who began at community colleges and were retained from fall to fall lags below $50 \%$ (National Student Clearinghouse, 2019). More specifically, the Fall 2017 to Fall 2018 cohort of first-time degree-seeking students at public two-year institutions had retention rates of $62.3 \%$ for full-time and $44.7 \%$ for part-time students (National Center for Education Statistics, 2019a). Graduation rates for community college students are also grim. At public two-year institutions, the $150 \%$ graduation rate for first-time, full-time students who entered in the Fall 2015 semester and planned on attaining a credential was 27.0\% (National Center for Education Statistics, 2019b). 
One factor which research has shown to be tied to various aspects of student success is moderate physical activity (Aung, Somboonwong, Jaroonvanichkul, \& Wannakrairot, 2016; Boyle, Mattern, Lassiter, \& Ritzler, 2011; Huesman, Brown, Lee, Kellogg, \& Radcliffe, 2009; Slade \& Kies, 2015). Slade and Kies (2015) concluded that among medical students, regular physical activity has a direct, positive relationship with exam grades. Huesman et al. (2009) illustrated that use of Campus Recreational Facilities was a strong predictor of retention and graduation.

Student interaction, both with peers and faculty, has been shown to improve student retention (Peck, 2011; Wirt \& Jaeger, 2014); sense of belonging, which leads to retention (Bippus, Kearney, Plax, \& Brooks, 2003; Skari, 2014; Tinto, 2017); and good grades (Bonet \& Walters, 2016; Grantham, Robinson, \& Chapman, 2015). Pressures including accreditations, performance-based funding, and low enrollment may consume time and efforts of community college leaders. But according to Lillis (2011), "It can be argued that every college and university has the capacity to construct conditions within the institution that motivate, inspire, and promote a student's desire to become an active member of a campus community" (p. 157).

\section{Background}

Lillis' (2011) argument has similarities to the inspiration for the current study, a true story from the researcher's family history, which occurred in the 1950s. At that time, a rookie elementary school physical education teacher named Tom found himself on playground duty with bullying problems. Talking and attempting to reason with the bullies were not effective long-term solutions. Using his knowledge of the positive effects of physical activity, combined with his engaging nature, Tom implemented "The 50-Mile Club." He understood that one effect 
of being physically active is having a positive self-image and hoped that participation in this club would change negative behaviors.

All students were invited to participate. The rules were simple: walk, jog, or run the perimeter of the ballfield. There were no requirements as to number of days, number of laps, or pace. With each lap, participants received one tally and encouragement from their beloved "Coach." Upon completing an aggregate of 50 miles, student names were posted prominently on a bulletin board in the school lobby. Tom saw an end to the bullying problem (T. Leavy, personal communication, October 19, 2016).

The importance of persistence and retention is rooted in community college missions. Open access is fundamental to the mission of community colleges in the United States (Boggs, 2011). Students who can benefit from an education at these institutions are welcome to attend, regardless of past performance, academic goals, or qualifications (Bahr \& Gross, 2016). As suggested by percentages of Pell Grant recipients by The National Center for Education Statistics (2018), the open access policy and the significantly lower cost of community colleges as compared to other institutions of higher learning result in high enrollments of students from low socio-economic backgrounds. Students from these circumstances are less likely than those in more stable financial situations to persist, be retained, and graduate (Schudde \& Goldrick-Rab, 2016). Therefore, community colleges face more of a challenge than their four-year counterparts in retaining students.

Currently, there is a nationwide problem of retention at community colleges. According to the National Student Clearinghouse (2019), fall-to-fall retention rates of first-time students at public two-year institutions have hovered below 50\% from 2009 to 2017 . For part-time students, the retention rates ranged from about $38 \%$ to $45 \%$ for the same time period. Students in public 
two-year colleges in cohort years 2007 through 2016 have had graduation rates fluctuate between $21.1 \%$ and 26.6\% (Juszkiewicz, 2019). Community college missions and performance-based funding require that these graduation rates increase; that can only happen if students persist and are retained.

Researchers have examined topics linked to improved persistence, retention, and graduation rates, and student success in general. For example, the literature supports moderate physical exercise as having a positive effect on better grades (Hillman, Erickson, \& Kramer, 2008), health benefits (American Heart Association, 2018), and student motivation (Aung et al., 2016). Additionally, student interaction was shown to positively influence student retention (Bonet \& Walters, 2016; Calcagno, Bailey, Jenkins, Kienzl, \& Leinbach, 2008; Trolian, Jach, Hanson, \& Pascarella, 2016). Further topics tied to persistence, retention, and graduation rates include fostering a sense of belonging (Hausmann, Shofield, \& Woods, 2007; Tinto, 1993), promoting healthy and active lifestyles (Melnyk, Kelly, Jacobson, Arcoleo, \& Shaibi, 2014; Withall, Jago, \& Fox, 2011), student success courses (Kimbark, Peters, \& Richardson, 2017), and learning communities (Bonet \& Walters, 2016).

Community college students have fewer opportunities than their four-year college counterparts to become engaged in campus life. Community colleges have fewer residence halls and facilities that promote socialization such as sporting venues or game rooms. Many students are part-time, have family responsibilities, and/or work 20 or more hours per week, and therefore their time for participation in campus life activities is limited (Karp, Hughes, \& O'Gara, 2010). Thus far, studies conducted relating to student persistence and retention were narrowly focused on some aspect of physical activity or student interaction. What is lacking in the literature is research on whether or not the combination of moderate physical activity on campus and student 
interaction with peers and college personnel have an effect on student retention. The current study investigated whether a walking program, which is a combination of moderate physical activity and student interaction, can be effective in improving student retention at a community college.

In the current study, the researcher sought to address the problem of poor retention rates at community colleges. Using quantitative methods, the researcher studied the effects on retention of a program that combined moderate physical activity in the form of walking, together with student interaction in the form of peer and college personnel conversations. The study occurred occur at Suburban Community College, a mid-sized community college in the northeastern United States. It was guided by Ajzen's Theory of Planned Behavior, since the "behavior" of a student who decides to persist or not is examined (Ajzen, 2006). Additionally, Tinto's (1993) Model of Institutional Departure is a guiding theoretical framework because it includes many of the constructs that contribute to a student's decision to stay in college or depart. The informal faculty/staff and peer group interactions, social integration, intentions, and institutional commitment are the constructs of particular interest in the current study. The researcher examined these theories in a context relevant to a problem plaguing higher education today: low student retention rates in community colleges.

\section{Purpose Statement}

The purpose of this study was to explore the effect of a voluntary walking program that combined moderate physical activity, student interaction with peers, and student interaction with college faculty, staff, and administrators, on student retention at a community college. The current study was guided by the following three research questions. 


\section{Research Questions}

1. Is there a relationship between participation in the walking program and retention?

2. Are the number of minutes walked associated with retention for the semester following the walking program?

3. Are the number of people spoken to while walking associated with retention for the semester following the walking program?

The current study was quantitative and took place in the Fall 2019 semester at Suburban Community College in the northeastern United States. The population was all students enrolled at Suburban Community College during the Fall 2019 semester. Recruitment occurred via orientation, classroom announcements, signs around campus, and social media. Due to the nature of the current study, convenience sampling had to be used. A matched sample for the control group was established via the Office of Institutional Research at Suburban Community College.

A Chi-Squared Test of Independence was conducted to answer the first research question to consider a relationship between the walking program and retention. For the second and third questions, a Fisher's Exact Test was used, first to consider any association between the number of minutes walked and retention, then to assess any association between the number of people spoken to during these walks and retention.

\section{Professional Significance}

Previous studies related to student retention have focused on distinct practices, including those that increase student interaction, to improve high attrition rates (Bonet \& Walters, 2016; Peck, 2011; Wirt \& Jaeger, 2014). Other studies in the literature addressed the importance of college students engaging in moderate physical activity to improve motivation and intelligence 
(Aung, Somboonwong, Jaroonvanichkul, \& Wannakrairot, 2016; Joubert, Kilgas, Riley, Gautam, Donath, \& Drum, 2017; Slade \& Kies, 2015). What is lacking in the literature is a study that combines moderate physical activity and student interaction and examines the effect of both variables on retention.

The current study was unique because the researcher addressed walking and student interaction together as independent variables and looked at their effect on the dichotomous dependent variable, student retention. Further, the approach of the researcher in the current study was unique because its focus was on a community college. These institutions have a unique population, partially due to their open access mission. Students who attend community colleges might not have been able to attend college at all due to poor grades in high school; the financial burden of attending four-year institutions; or personal reasons such as caring for a parent, raising a child, or being employed in one or more jobs.

Community college presidents, academic vice presidents, and retention specialists have a vested interest in improving student retention. Retaining students results in higher enrollment rates which correspond to full-time equivalent (FTE) metrics, and ultimately funding that relies on FTEs. Further, retention rates are tied to performance-based funding, another reason for these same stakeholders to be interested in improving retention rates.

Low enrollment is a function of decreasing incoming class sizes and high attrition rates. Demographics cannot be controlled and therefore increasing the number of new students can be challenging. The literature indicated that reducing attrition rates is doable (Tinto, 1993). Since lower enrollment means fewer students and, therefore, fewer classes as well as a decreased need for space, all college stakeholders must be concerned about the need to address the problem of student retention at community colleges. The jobs of faculty, student services personnel, food 
service employees, security guards and maintenance workers could be in danger if enrollment numbers are too low. Therefore, the results of the current study are of interest to all stakeholders at community colleges.

\section{Overview of the Methodology}

Guided by the extant literature, the current study used variables that have been linked to motivation, good grades, sense of belonging, and retention. The impact of both moderate physical activity and student interaction on a student's decision to re-enroll at Suburban Community College for the Spring 2020 semester was considered. The current study was approached from a post-positivist perspective. That is, there is inherent bias in any study related to human behavior, and results concerning students at community colleges should not be seen as exact truths (Leedy \& Ormond, 2016).

The study took place at "Suburban Community College," a suburban community college in the northeastern United States, during the Fall 2019 semester. Suburban Community College enrolls approximately 5,000 students and has had continuously decreasing enrollment since 2011. Fall-to-fall retention rates hover around $63 \%$ for full-time students, and $47 \%$ for parttimers (National Center for Education Statistics, 2019c). Therefore, Suburban Community College is a community college that will benefit from research on increasing retention.

The population was all students enrolled at Suburban Community College during the Fall 2019 semester, except those who graduated or transferred in December 2019. Recruitment for the study's sample began at the end of the Spring 2019 semester, with information disseminated to college personnel via verbal announcements at Cabinet, college-wide governance, and the college's Wellness Advisory Board meetings. College employees were asked to encourage 
students to participate in the walking program during the Fall 2019 semester, and to join in the program themselves, engaging students in conversation.

At the commencement of the Fall semester, students were recruited via electronic monitors on campus, fliers on bulletin boards, orientation, social media, and faculty announcements. Due to the nature of the current study, convenience sampling was used. Any student who entered at least one data value in their Google sheet (Appendix A) was considered as part of the sample. A matched sample based on gender, ethnicity, Pell eligibility, age, and semester enrolled for the control group was established via the Office of Institutional Research at Suburban Community College.

During the Fall 2019 semester, students were invited to walk on campus at any time. Any student enrolled at Suburban Community College for that semester was welcome to participate. For each day that they walked, they made an entry on their Google sheet for each of the two independent variables: "number of minutes walked" and "number of people spoken to while walking." Additionally, they indicated if they walked "on or near campus" or "off campus." Thus, the study was quantitative with data gathered on Google sheets, each of which was shared between only the student participant and the researcher. The sheets contained formulas to convert "number of minutes walked" to "number of miles walked," using the conversion of a 20 minute per mile pace (Hoeger, Bond, Ransdell, Shimon, \& Merugu, 2008). The number of minutes walked and number of people spoken to were each summed automatically every time an entry was made, and a hidden formula calculated the cumulative number of miles walked. This number was tracked graphically so that each student was able to see their progress of cumulative miles walked on his or her sheet. The dependent variable was "enrollment at Suburban Community College in the Spring 2020 semester," a dichotomous 
variable. The numeral 1 corresponded to a student enrolling, and 0 meant a student did not enroll in the Spring 2020 semester.

Two attempts to motivate students to participate in the walking program were made. First, any student who enrolled in the program and participated at least until November 1 was entered in a drawing to win a $\$ 100$ American Express gift card. Second, there was the opportunity for recognition. Data were monitored weekly by the researcher to see how students were progressing. Any time a student reached 10, 25, or 50 miles, his or her name was posted on a banner in a prominent place in the center of each campus. Additionally, any student who completed 50 miles received a bumper sticker (Appendix F) that stated "I walked 50 miles at Suburban Community College." At the conclusion of the semester, all students' totals were gathered and summarized on one spreadsheet (Appendix C).

\section{Delimitations}

- The study took place at one mid-sized community college in a northeastern state in the United States.

- The study considered walking as the mode of moderate physical activity.

- The study was quantitative.

- The study was confined to one Fall semester.

- The variables studied were (1) number of minutes walked, (2) number of people spoken to while walking, (3) number of days walked, and (4) whether or not a participant registered for class(es) for the Spring 2020 semester.

- The study used Google sheets for data collection. 


\section{Operational Definitions}

- Cognition - conscious mental activities; these can include perceptual skills, intelligence quotient, achievement, verbal tests, mathematic tests, memory, developmental level/academic readiness and other (Hillman, et al., 2008).

- Completion - the act of attaining any formal award conferred by the institution (American Association of Community Colleges, 2019).

- Moderate physical activity - "any bodily movement produced by skeletal muscles that requires energy expenditure... such as walking, cycling, or doing sports." (WHO, 2018, \1).

- Performance-based funding - a system used by a funding source, usually a state, to allocate funding to an institution based on student achievement of intermediate metrics such as completion of a certain number of credit hours, completing developmental coursework, earning a certificate or degree, transferring to a four-year institution (McKinney \& Hagedorn, 2017).

- Persistence - the act of a student staying in college.

- Student interaction - any type of interpersonal communication involving students. For the purposes of the current study, student interaction is conversations involving students.

- Student retention - an institutional goal of having students remain in college. In particular, a student enrolled in the Fall 2019 semester who registers for at least one class in the Spring 2020 semester is considered retained.

The current study was designed to expand the body of literature concerning student retention at community colleges. Specifically, it focused on a combination of moderate physical activity and student interaction and the effect of these two constructs on student retention. The 
next chapter is a review of literature related to topics in the current study. The methodology for the study used to answer the research questions is described in Chapter 3. In Chapter 4, the data are analyzed, and the findings are presented in Chapter 5. 


\section{CHAPTER 2}

\section{Literature Review}

The current study was concerned with community college students and whether or not interaction together with moderate physical activity contribute to a student's decision to persist. Unlike typical undergraduates at four-year institutions, many community college students do not have the traditional opportunities for joining clubs or athletic teams. Further, the profile of community college students differs from that of students in four-year colleges. Students at community colleges are more likely than their peers at four-year institutions to have one or two jobs; many are parents or are caring for a loved one at home; others are first-generation students who may need special attention (Karp, Hughes, \& O'Gara, 2010; Shannon, Smith, Townsend, \& Dougherty, 2006; Wirt \& Jaeger, 2014). Therefore, students at two-year colleges do not have the ability to spend all day at school attending class, participating in club meetings, and/or going to a college athletic event.

\section{Purpose Statement}

The purpose of this study was to explore the effect of a voluntary walking program that combined moderate physical activity, student interaction with peers, and student interaction with college faculty, staff, and administrators, on student retention at a community college.

\section{Method of the Literature Review}

Key constructs of the purpose statement were "physical activity," "student interaction," "student retention," and "community college." The literature search was conducted with Firefox in the Old Dominion University library databases, the Orange County Community College databases, and Google Scholar. When searching for reference materials, the following keywords 
and phrases were used: "student interaction," "physical activity," "community college," "retention," "student-to-student interaction," and "student-to-faculty interaction."

In order to be included as a reference, an article was required to be peer-reviewed, and deemed relevant and acceptable to the researcher. Another criterion was that the article be written within the last 10 years, unless it significantly added to the quality of the research. For example, throughout the review of the literature concerning student interaction, recent authors frequently cited the works of Pascarella and Terenzini, whose research began in the 1970s and continued for three decades. Their contribution to scholarly work related to student interaction was deemed important to the current study.

\section{Theoretical and Conceptual Frameworks}

Two theoretical frameworks were used to guide this study: Ajzen's Theory of Planned Behavior and Tinto's Model of Institutional Departure. Ajzen's (2006) theory as depicted in Figure 1 illustrates that the three constructs: attitude, subjective norms, and perceived behavioral control predict intention. Intention, in turn, predicts behavior. As this theory relates to the current study, the attitude is a student's question "What do I think about staying in college?" Regarding subjective norms, a student would ask "What will others think about my staying?" The student's question to him- or herself regarding perceived behavioral control would be "Can I do it?" If the answers to these questions allow a student to intend to re-enroll, then the resulting behavior would be to sign up for classes the following semester (Rhodes \& Nigg, 2011). 


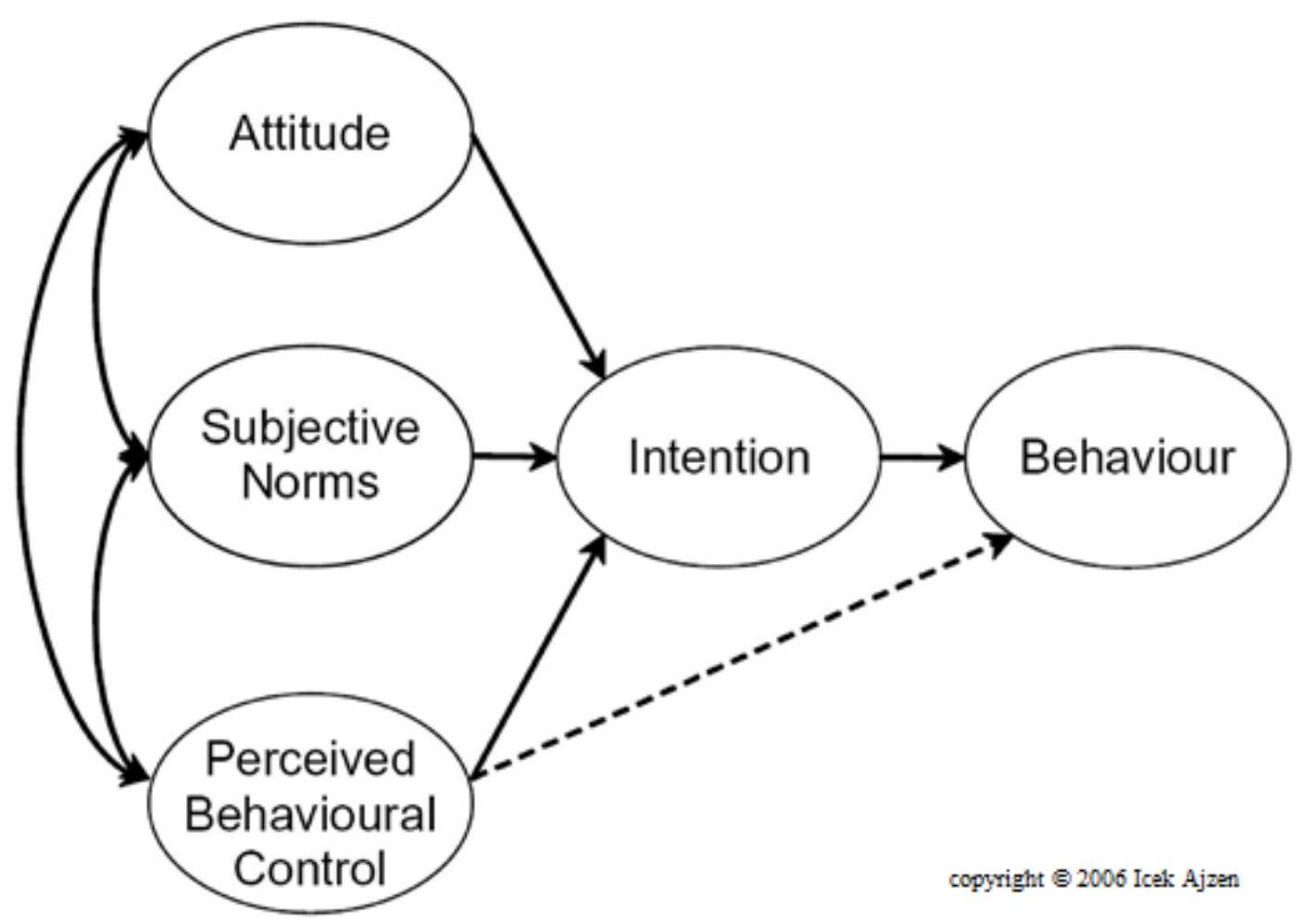

Figure 1. Ajzen's theory of planned behavior

Tinto's Theory of Institutional Departure (Tinto, 1993) contained many constructs which ultimately lead to a college student's decision to leave college or not (Figure 2). Of particular relevance to this study are the informal faculty/staff and peer group interactions, and the social integration that results, which leads to intentions and institutional commitment, and ultimately the decision to leave or stay. A moderate physical activity, such as walking in the program for the current study, may provide the social integration to which Tinto (1993) referred.

Interestingly, there is a similarity between the final stages of Ajzen's and Tinto's theories. Both conclude with some version of intention leading to an act, or behavior. 


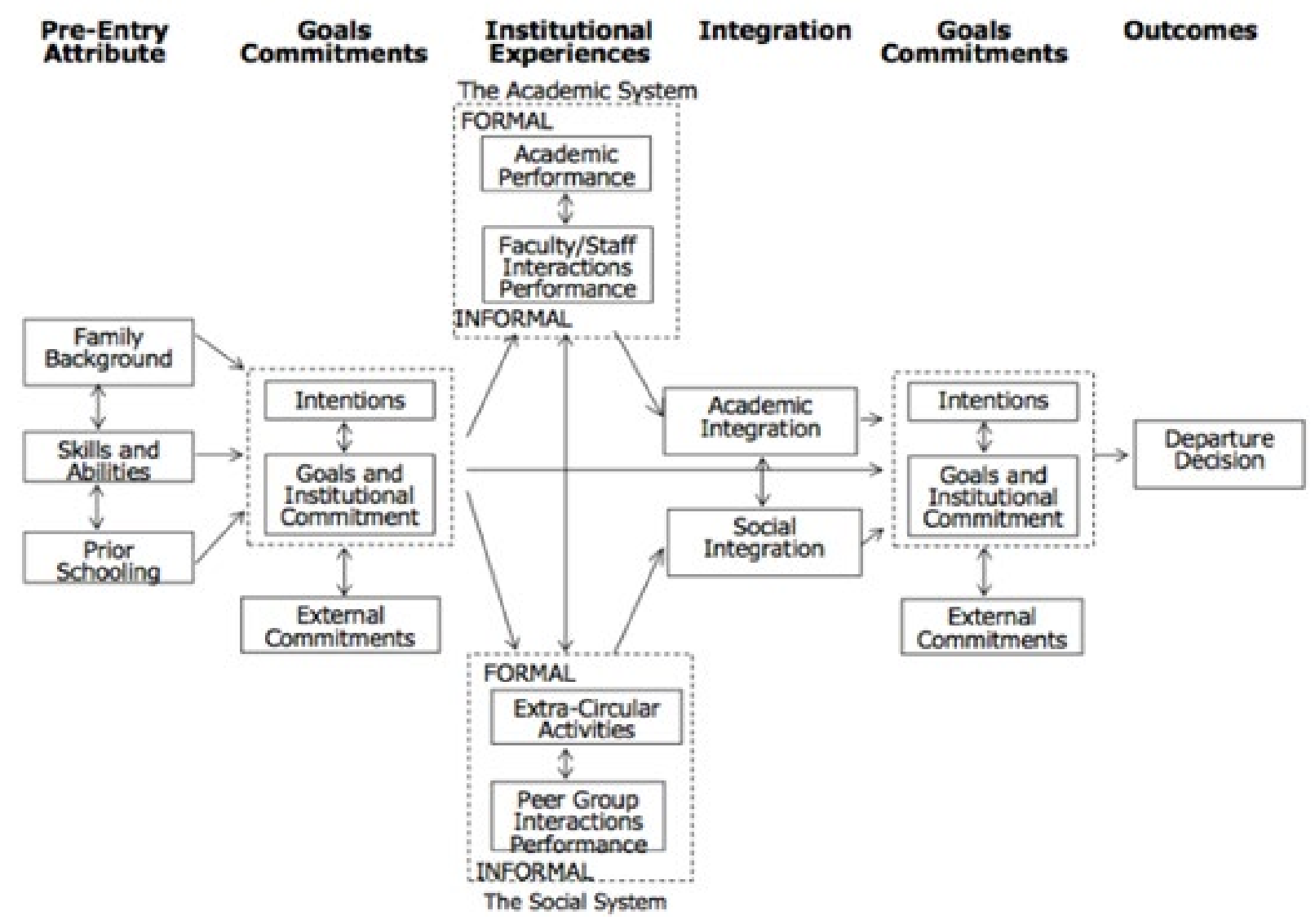

(c) (7) (2)

Figure 2. Tinto's longitudinal model of institutional departure

Based on the literature, the conceptual framework in Figure 3 was created by the researcher. 


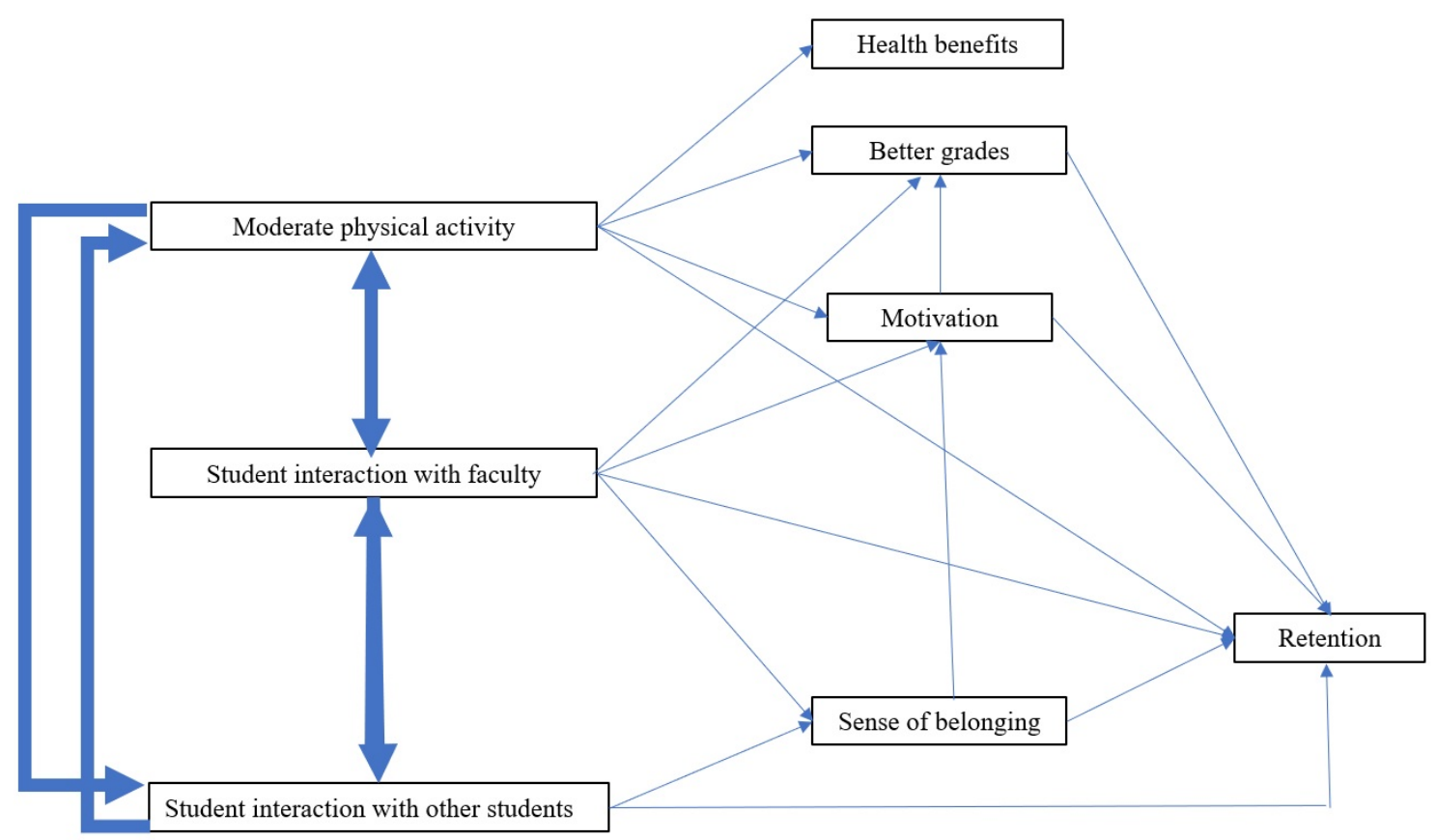

Figure 3. Conceptual framework for the current study

The thin arrows represent conclusions made from the extant literature. The thick arrows are what the current study hopes to contribute to the current knowledge about student retention at community colleges. Following a review of the literature, the conceptual framework is presented again with authors who established the connections represented by the thin arrows.

\section{Physical Activity}

The importance of physical activity for good health is well-documented. The World Health Organization (2017) defined physical activity as "any bodily movement produced by skeletal muscles that requires energy expenditure" ( 1 1). Running, swimming, biking, engaging in sporting activities, walking, and even doing household activities constitute physical activity (Tucker, Welk, \& Beyler, 2011). According to the American Heart Association (2017), adults should spend a minimum of 150 minutes per week engaging in moderate-intensity aerobic 
physical activity, or 75 minutes per week if the activity is of vigorous-intensity. This exercise should be done in increments of at least 10 minutes and spread throughout the week. The compliance results of Americans for these benchmarks were similar in years 2008 and 2016.

The United States Department of Health and Human Services, or USDHHS, (2018) used metabolic equivalent of task, or MET, to define moderate-intensity activities. A MET "is a unit useful for describing the energy expenditure of a specific activity" (USDHHS, 2018, p. 106). Any activity between 3.0 and 5.9 METs is considered to be of moderate intensity. An example of a moderate-intensity activity is walking at three miles per hour, since the MET for that activity is 3.5. The current walking program used 20 minutes of walking to be the equivalent of one mile, which is exactly three miles per hour.

Accelerometers. Tucker et al. (2011) studied the compliance of Americans with the 2008 USDHHS recommendations. The authors used both interviews and accelerometers for data collection. An accelerometer is a device worn on the body that estimates movement metrics including number of steps taken, miles covered, and heartrate. The interviews required that participants self-report their physical activity over the previous 30 days. Tucker et al. (2011) found from using accelerometry data that $45 \%$ of Americans spent 150 minutes per week engaging in moderate-intensity aerobic activity and 18\% engaged in 75 minutes per week of vigorous-intensity activity. Males had better results than females, and those in the 20-29 age group performed best of all age groups.

Another finding by Tucker et al. (2011) was the difference between self-reporting and using an accelerometer to record physical activity. They found a significant overestimation of physical activity when individuals self-report: $62.0 \%$ of self-reporters met the United States Department of Health and Human Services' minimum guideline of 150 minutes of moderate 
physical activity per week, but only $9.6 \%$ of those using accelerometers met that guideline.

These results were supported by a similar study by Slootmaker, Schuit, Chinapaw, Seidell, and VanMechelen (2009). Additionally, Downs, van Hoomissen, Lafrenz, and Julka (2014)

conducted a more recent and similar study and focused solely on college students. Their results were the same: those who self-report physical activity overestimate data.

In a non-peer-reviewed article, Sherman (2017) described a very successful program at Oral Roberts University. Participation in health and fitness activities is mandatory there, and students used to record data on paper, then submit these papers to a faculty member. The instructor then manually entered these data into the grading system. In the Fall of 2015, another option was offered to students: wear an accelerometer. Almost all students chose this option, and the college saw great success with the program; both students and instructors were enthusiastic about the new approach.

Benefits. Individuals have much to gain by engaging in physical activity. Being physically active increases life span, helps control blood pressure and weight, and can help lower the risk of heart disease, stroke, depression, and Type 2 diabetes. Other benefits include socialization, strengthening bones and muscles, and sleeping better (American Heart Association, 2018; Office of Disease Prevention and Health Promotion, 2020; Sallis, 2009).

Physicians and other health care professionals are keenly aware of the role physical exercise plays in disease prevention and improvement in quality of life (Lobelo, Stoutenberg, \& Hutber, 2014; Sallis, 2009). Sallis (2009) noted the recognition throughout history of the link between regular physical activity and good health, dating back to Hippocrates in the fifth century BC. Sallis (2009) described a theoretical pill that would address many health maladies. This socalled exercise pill would be prescribed by doctors as medicine for preventing the onset of 
certain diseases. Sallis (2009) called for all physicians to evaluate patients' physical activity levels as a vital sign. This measurement is the number of minutes per week a patient spends engaging in at least moderate-level exercise. According to Sallis (2009), after a full examination, the doctor should prescribe exercise as medicine, and write the prescription on paper similar to that of a medicinal prescription.

Exercise is medicine. The acknowledgement of exercise as being medicine is the basis for the 2007 initiative launched jointly by the American Medical Association and the American College for Sports Medicine entitled Exercise is Medicine, or EIM, (Lobelo, Stoutenberg, \& Hutber, 2014; Sallis, 2009). The EIM mission is to promote physical activity to optimize good health and prevent and treat several medical conditions. Additionally, EIM believes that physical activity should be part of every health assessment and treatment plans should be prescribed as needed. Finally, patients should be referred to participate in exercise programs that are evidence-based (Exercise is Medicine, 2018). Since its inception in 2007 in the United States, EIM has turned global and is now in over 40 countries on five continents (Lobelo et al., 2014).

According to Bopp, Bopp, Duffey, Ganim, and Proctor (2015), EIM expanded its mission in 2009 to include college students in their Exercise is Medicine on Campus initiative. Since that time, EIM on Campus now has presence in 168 institutions of higher learning in the United States and 17 internationally (Exercise in Medicine, 2018). EIM on Campus uses many programs to promote physical activity, including five-kilometer races, exercise classes, and fairs. Colleges and universities became a focal point for EIM because of the volume of young adults that could be reached, the availability on college campuses of recreational facilities, and the networking capabilities for sharing implementation strategies and results among campuses. 
Bopp et al. (2015) studied the implementation and efficacy of an EIM on Campus program at a large United States university. Key findings of their study included the success of exercise stations set up on campus and the enthusiasm of student volunteers from across the campus, led by members of the Kinesiology Club. Melton, Williamson, Bland, and Zhang (2016) used quantitative analyses to conduct a similar study in a mid-sized rural university in the southwestern United States. Like Bopp et al. (2015), Melton et al. (2016) implemented EIM on Campus, but their secondary goal was to study the beliefs and practices of college students concerning physical activity. In their study, they found that the commitment of college students to participating in regular physical activity was consistent with national data: less than half met the minimum recommendations of the AHA. Further, they found that minorities were less likely than whites to engage in vigorous activities, and males were far more likely than females to be motivated to exercise for social and enjoyment purposes.

Medical-related research. Although they did not specifically refer to the Exercise is Medicine initiative, Nagamatsu, Flicker, Kramer, Voss, Erickson, Hsu, and Liu-Ambrose (2014) discussed exercise as medicine as it relates to cognitive function. They cited several studies that linked low physical activity to slowing cognitive decline. According to Sathyanarayana-Rao and Tandon (2016), cognition means "a high level of processing of specific information including thinking, memory, perception, motivation, skilled movements, and language" (p. 1). Studies have found strong relationships between physical activity and cognition in the context of medical research (Hillman, Erickson, \& Kramer, 2008; VanKim \& Nelson, 2013). Hillman et al. (2008) did a meta-analysis of scientific research of the brain and how it functions with and without physical exercise. Their research definitively showed that being physically active, particularly engaging in aerobic exercise, positively influences cognitive function. Additionally, they 
concluded that physical activity provides life-long positive effects, even for patients with neurodegenerative diseases. These results suggested that all people, students in particular, can benefit cognitively from physical activity.

Another medically focused study researched four-year college students and addressed how vigorous physical activity related to mental health, perceived stress, and socializing (VanKim \& Nelson, 2013). Students were asked about the frequency of their participation in physical activity that made them "sweat or breathe hard, such as basketball, soccer, running, swimming laps, ...” (p. 8) for a minimum of 20 minutes. Mental health, stress, and socialization were measured by answers to a standardized survey. The study had a very large sample size of over 14,000, and results showed a strong negative correlation between vigorous physical activity and both poor mental health and perceived stress. The conclusion by VanKim and Nelson (2013) that the social component of physical exercise was instrumental in this correlation is of particular interest to the current study.

Zhu, Haegele, and Healy (2019), who also had a large sample size, confirmed some of VanKim and Nelson's (2013) results for a younger population. They studied physical exercise as it related to mental health in youth and adolescents. They found there is a negative correlation between physical activity and anxiety or depression for this population.

Cognition. Research found in the literature included studies that were less medical and more social science oriented. These studies showed or built upon positive links between physical activity and cognition (Aung, Somboonwong, Jaroonvanichkul, \& Wannakrairot, 2016; Huesman, Brown, Lee, Kellogg, \& Radcliffe, 2009; Slade \& Kies, 2015). Huesman et al. (2009) and Slade and Kies (2015) focused on the use of campus recreational facilities (CRFs) and student success. CRFs are mostly indoor facilities that provide many options to engage in 
physical activity including pools; racquetball, tennis and basketball courts; weight, spinning, and dance rooms; and tracks.

Slade and Kies (2015) concluded that among medical students, regular physical activity has a direct, positive relationship with exam grades. In their analysis, Slade and Kies (2015) tracked four different cohorts of first-year medical students for use of the CRF and exam scores. It was found that for students who stopped using the CRF because an exam was upcoming, there was no increase in the mean exam score; the grades actually decreased. There was a direct relationship between use of CRFs and mean grades in both directions: as use of CRFs increased, so did the mean exam grades and as use of CRFs decreased, the mean exam grades also declined. These results indicated that an exercise program may be beneficial for students' grades.

Huesman et al. (2009) looked beyond student grades; they studied CRF use as it related to retention and graduation rates. They used quantitative methods to gather and analyze data and had a reliable method for objectively counting student visits to CRFs: electronic scanning of college identification cards. Logistic regression models were used to analyze the dichotomous dependent variables of first year retention and graduation. The results showed that use of CRFs was a strong predictor of retention and graduation.

Slade and Kies (2015) and Aung et al. (2016) studied physical activity of medical students. As discussed earlier, Slade and Kies (2015) concluded that there was a strong relationship between physical activity and grades of medical students. Aung, et al. (2016) looked at physical activity and its effect on motivation of medical students in Asia. They distinguished between intrinsic motivation, which is the desire to study because of personal reasons, and extrinsic motivation, the desire to study because of an outside influence such as 
family pressure or receiving an award. Aung, et al. (2016) found a strong relationship between physical activity and intrinsic exercise among Asian preclinical medical students.

Lifestyles. Today's college students have lifestyles that encourage physical inactivity: they spend many hours each day on electronic devices (Lepp, Barkley, Sanders, Rebold, \& Gates, 2013), are prone to long hours of sedentary behavior (Joubert, Kilgas, Riley, Gautam, Donath, \& Drum, 2017), and contend with stress and weight issues (Pelletier, Lytle, \& Laska, 2016). According to Smith and Anderson (2018) in a report for the Pew Research Center, of 18to 29 -year-olds who use the internet, $81 \%, 91 \%, 64 \%$ and $68 \%$ use Facebook, YouTube, Instagram, and Snapchat, respectively. They also found that $78 \%$ of 18 - to 24 -year-olds, which is the majority age range of college students, use Snapchat, and $71 \%$ of these users frequent that application several times per day.

Lepp et al. (2013) studied cell-phone use, sedentary activity, and cardiorespiratory measurements of college students at a large mid-western university in the United States. The results were strongly significant: high usage of cell phones correlates positively with sedentary activity and poor cardiorespiratory fitness. Despite that relationship, Lepp et al. (2013) conceded that there are opportunities for cell phone use to increase physical activity: users can walk while using their phones and there are applications available that promote physical fitness.

Programs. The recognition by higher education of the importance of physical activity in American college students dates back almost 100 years. According to Geiger (2016), the origin of physical activity in higher education in the United States occurred in the early $20^{\text {th }}$ century with the inception of student-run organizations, activities and sports. Interest in these programs continues today. Currently, physically engaging activities occur on college campuses as physical education courses and other formalized courses or programs outside a physical education 
department, some more successful than others (Boyle et al., 2011; Melnyk, Kelly, Jacobson, Arcoleo, \& Shaibi, 2014).

Melnyk et al. (2014) studied the success of a three-credit course entitled Freshman 5 to Thrive/COPE Healthy Lifestyles offered at a large southwestern university in a U.S. city. COPE is an acronym for Creating Opportunities for Personal Empowerment. Freshmen residing in a healthy-living dormitory were required to take this course and comprised the experimental group; data from this group were compared to a control group, freshman who did not enroll in the course. The Freshman 5 to Thrive/COPE Healthy Lifestyles course covered five main areas of focus, one of which was physical activity. The authors found this course had a significant impact on the students in the experimental group related to many aspects of healthy lifestyles, including physical activity. Further, these students were more likely to be retained.

A less successful course-based physical activity program involved healthy freshmen in a four-year comprehensive institution who were separated into two groups, both of whose members set goals for increasing physical activity (Boyle et al., 2011). The intervention group had one-on-one peer mentoring sessions with advanced exercise physiology students; the control group worked toward their goal as individuals. Some results in women were positive, but there were no significant differences between the two groups for men.

Educators today recognize the importance of physical activity in college students as illustrated by the presence of physical education departments, intercollegiate and intramural sports, and course-based and extracurricular physical activity programs such as Exercise in Medicine on Campus. Young, Sturts, and Ross (2015) posited that students may not be aware of the health risks of physical inactivity. They studied community college students and their perceived levels of physical activity. Of the 655 students in the study, $65 \%$ claimed they were 
physically active, but only $75 \%$ of those reported engaging in regular physical activity. Of those who stated they are not physically active, $89 \%$ indicated they intended to engage in regular physical activity in the next 6 months. Interestingly, $60 \%$ of the sample studied were overweight or obese. Young, Sturts, and Ross (2015) conducted this study to set a baseline for community college students' perception of being physically active.

Exercise among community college populations. Open access is fundamental to the mission of community colleges in the United States (Boggs, 2011). Students who can benefit from an education at these institutions are welcome to attend, regardless of past performance, academic goals, or qualifications (Bahr \& Gross, 2016). The open access policy and the significantly lower cost of community colleges as compared to other institutions of higher learning result in high enrollments of students from low socio-economic backgrounds (National Center for Education Statistics, 2019d).

Withall, Jago, and Fox (2011) noted that people from economically disadvantaged populations are less likely to engage in physical activity than those living at middle- or higherincome levels. They found that individuals residing in depressed neighborhoods are challenged by the barriers of cost and childcare that decrease their likelihood to engage in physical exercise. Young, Spengler, Frost, Evenson, Vincent, and Whitsel (2014) recognized this inequity concerning socio-economic status and participation in physical activities and recommended that schools share their recreational facilities with community members. Such a sharing of resources would not only benefit those attending the institutions with the facilities, but also members of surrounding communities.

Walking. There is one option for engaging in physical activity that is available to almost everyone, regardless of socio-economic status or athletic ability. Walking is a physical 
activity that requires neither money nor equipment and is safe for most people (Centers for Disease Control and Prevention, 2019; Ball, Abbott, Wilson, Chisholm, \& Sahlqvist, 2017; National Physical Activity Plan Alliance, 2018). It can be easily incorporated into the day by those choosing not to drive to a local destination or parking far from a destination.

The National Physical Activity Plan Alliance, or NPAPA (2016), dedicated a full report to walking as a physical activity. The authors of the report focused on reaching all populations of Americans, including every level of socio-economic status, race, gender, age, and physical ability. This report was based upon the U.S. National Physical Activity Plan (NPAP, 2016), which made recommendations concerning increasing physical activity in Americans in nine sectors, one of which was Education. For the twenty million students in higher education, one recommendation was to promote "opportunities and incentives for college and university students to adopt and maintain physically active lifestyles" (NPAPA, 2016, p. 16).

Ball et al. (2017), who studied walking programs in Australia, and AHA (2017) made suggestions for getting started and continuing with a successful walking program. Ball et al. (2017) focused more on large-group walking programs, and their study resulted in recommended strategies for sustainability: Make the program free and have a social component. Offer incentives and rewards for achieving milestones. Embed the program in and have it supported by the local community. The AHA (2017) was more focused on individuals' walking programs. Topics covered included injury prevention, proper attire, and the benefit of walking with others.

A meta-analysis conducted by Kassavou, Turner, and French (2013) synthesized results of 19 studies related to walking programs. They concluded that walking groups as interventions were efficacious at improving physical activity in adults. Specifically, walking groups as interventions involving both genders were more significant in promoting physical activity than 
walking interventions for women only. The authors encountered no acceptable studies for menonly walking groups.

This literature review illustrates that physical activity is extremely important for human beings. Weekly recommendations for physical activity were given by the AHA (2017) and the USDHHS (2018). Benefits include the prevention of a variety of diseases such as obesity, type 2 diabetes, and heart disease. Physical activity also has been shown to improve sleep habits and increase socialization (AHA, 2017; Office of Disease Prevention and Health Promotion, 2020; Sallis, 2009). The Exercise is Medicine initiative (Bopp et al., 2015, Lobelo et al., 2014, Melton et al., 2016, \& Sallis, 2009) aims to increase physical activity and, as a result, promote healthy lifestyles and prevent medical conditions. Physicians who are part of the EIM initiative assess exercise and prescribe it just as they would medicine.

This review of the literature illustrates connections between physical activity and cognition. Hillman et al. (2008), Nagamatsu et al. (2014), and VanKim and Nelson (2013) used medical evidence to make that connection. The research of Aung et al. (2016), Huesman et al. (2009), and Slade and Kies (2015) showed links between physical activity and grades and retention. Joubert et al. (2017), Lepp et al. (2013), Pelletier et al. (2016), and Smith and Anderson (2018) studied the lifestyles of college students of today. Lepp et al. (2013) showed that high usage of cell phones correlates positively with sedentary activity and poor cardiorespiratory fitness. Institutions of higher education recognize that physical activity is important (Geiger, 2016), and programs promoting it have been implemented in colleges (Boyle et al., 2011; Melnyk et al., 2014; Young et al., 2015).

Finally, this review of the literature shows that walking is a simple, inexpensive and social source of physical activity that is an option for most people (Centers for Disease Control 
and Prevention, 2019; Ball et al., 2017; NPAPA, 2018). Recommendations for walking programs for individuals and groups were offered by the AHA (2017), Ball et al. (2017), and NPAPA (2018). In a meta-analysis of several studies of walking, Kassavou et al., (2013) found that walking groups led to better physical activity in adults.

\section{Community College Students}

From the inception of two-year institutions of higher education in 1901 with Joliet Junior College (Vaughn, 2006), a new opportunity for education was available to many who might not have ever had the chance to attend college. Community colleges provide an open access policy, enabling anyone who can benefit from an education there to attend (Shannon, Smith, Townsend, \& Dougherty, 2006). As a result, the characteristics of community college students differ from those of their four-year institution counterparts.

Karp, Hughes, and O'Gara (2010) described profiles of many community college students: they typically do not live on campus and many have jobs to support family and pay tuition; some work full-time, while others have multiple part-time jobs. Many have obligations to attend to such as caring for children or an elderly family member. According to Wirt and Jaeger (2014), because many community college students work part-time, they have minimal interaction outside the classroom. Shannon, et al. (2006) added ethnic minorities, women, developmental, and first-generation students to the list of characteristics of typical community college students.

Pascarella, Wolniak, Pierson, and Terenzini (2003) focused specifically on firstgeneration community college students. Using multiple regression on data from five community colleges in the U.S., they studied seven dependent variables which covered students' cognitive development, orientation to learning, and educational plans. The results were grim; some 
conclusions were: first generation students had lower grades; studied less; accumulated fewer credits; took fewer Science, Technology, Engineering, Arts, and Math (STEAM) courses; and worked more than their counterparts whose parents both attained at least a bachelor's degree.

The description of community college students is important to the current study. Due to the characteristics just described, these students do not have the time to participate in activities that would provide integration with the college community (Karp, et al., 2010). Therefore, these students are less likely to feel the important sense of belonging that facilitates keeping them in college (O'Keeffe, 2013; O'Riordan, \& Broughton, 2017; Tinto, 1993). Further, Kuh (2016) referred to students at all colleges and universities in the U.S. and identified eight characteristics of students that threaten their persistence: "academically underprepared for college-level work, first-generation college student, gap between high school and college, thirty or more hours working per week, part-time enrollment, single parent, financially independent, and children at home" (p. 51). O'Keeffe (2013) provided risk factors linked to high attrition rates of college students in the U.S. and Australia. These included ethnic minorities, students who are academically disadvantaged, and students of low-socioeconomic status. These are precisely the characteristics of today's typical community college student.

Another more recent dynamic that limits college students' integration is technology. Interestingly, this issue was raised by John Dewey (1927) who wrote about education and pedagogy in the late 1800s and early 1900s. Referring to the technologies of radios, telephones, and cinemas, Dewey acknowledged their positive effects which included broadening communication and removing physical barriers. However, he also cautioned against these technologies, which were new in his lifetime. "Our concern at this time is to state how it is that the machine age in developing the Great Society has invaded and partially disintegrated the small 
communities of former times..." (p. 314). The argument made by Dewey (1927) concerning technologic advancements diminishing small communities, including one-on-one dialogues, could also be made in the $21^{\text {st }}$ century.

Today, there are myriad additional technologies infused in our society; social media is among them. Smith and Anderson (2018) provided statistics about social media use for adults between the ages of 18 and 24 :

- $82 \%$ of those using Snapchat use it daily

- $71 \%$ use it more than once per day

- $81 \%$ of this population use Instagram daily and $55 \%$ use it multiple times per day

- $51 \%$ of adults in this age group believe it would be difficult to live without social media Lepp, et al. (2013) stated that college-age students spend up to five hours per day on their mobile devices.

Cyber-slacking is the concept of college students using mobile technology for off-task activities during classroom lectures or while outside the classroom during time allotted for homework (Flanigan \& Kiewra, 2018). Flanigan and Kiewra (2018) described this behavior as "chronic and addictive" (p. 587). Bjornsen, Archer, Gurung, and Landrum (2015) studied the relationship between university students' in-class cell phone use and exam grades. Despite the fact that community college students were not part of the sample, the mean age of students was 20.0 years, and the age range was $18-23$. The results of this study are helpful in understanding cell phone use and its effects on young adults in college. Bjornsen, et al. (2015) found that regardless of gender or grade point average, student cell phone use in class has a negative impact on grades. 


\section{Student Interaction}

Student interaction, defined for this study as student conversation, is often associated with participation in athletics, student clubs, or other on-campus activities. From a historical perspective, it was not until the early $20^{\text {th }}$ century that student-run organizations, activities, and sports became largely associated with American higher education. According to Geiger (2016), there was an "explosion" of such organizations "with the rise of football being the most prominent" (p. 20). As interest by prospective students, alumni, and other donors grew, so did a huge source of revenue for colleges and universities that continues to this day.

Since most community colleges do not have large athletic programs and are commuter schools, they do not provide the same opportunities for interaction that four-year institutions have. Tinto (1993) acknowledged this fact yet claimed that community college students' informal contact with faculty does contribute to students' decisions to persist. Karp, Hughes, and O'Gara (2010) did a qualitative study testing Tinto's (1993) framework specifically on community college students and found it to be very applicable. Of particular interest to the current study, they concluded "[community college] students who are isolated, or who do not engage in social interactions within the college, are less likely to persist in the institution" (p. 71). The following two sections examine a review of the literature on faculty-student interaction and student-student interaction.

\section{Faculty-Student Interaction}

Research concerning faculty-student interaction includes considering differences between interaction with full-time versus part-time faculty (Bippus, Brooks, Plax, \& Kearney, 2001), levels of interactions with faculty between female and male students (Cohen, 2018), and the effects of faculty-student interaction that occurs through learning communities (Bonet \& 
Walters, 2016). Bippus, et al. (2001) concluded that students usually have no indication of whether their faculty members are full- or part-time, or what their rank is. Regardless of their instructors' statuses, students who seek mentoring by their faculty are more concerned with academic or career questions or finding a sense of belonging in a college that may feel impersonal. Sense of belonging, as discussed later, serves as a mediating variable between faculty-student interaction and retention.

Cox (2011) created a typology of different faculty-student interactions: disengagement (no interaction), incidental, functional, personal, and mentoring. A student and instructor accidentally meeting constitutes incidental interaction. Functional refers to interactions that deal primarily with academics, such as office hours or working together on a research project. Personal interaction is purposeful and occurs when conversations include personal interests of either the student or instructor. Finally, mentoring, which Cox (2011) found to be exceptionally rare, occurs when a student and faculty member form a relationship that encompasses both functional and personal types of interaction. Thus, the different types of faculty-student interactions are not mutually exclusive. Of interest to the current study was the following conclusion made by Cox (2011):

The transition to personal interaction was powerful because it marked a fundamental shift in the nature of the relationship. It was at this point that students began to recognize faculty members as 'people' and to feel valued as unique individuals, peers, or even friends of the faculty members. The faculty members' concern for student well-being and success became clear to the students. Moreover, students often expressed some surprise when they 
described, often with great animation, the 'fun' and 'interesting' personal

conversations they would have with faculty members. (Cox, 2011, p. 52)

Such recognitions by students constitute a sense of belonging.

Student motivation is another mediating variable between faculty-student interaction and retention. Komarraju, Musulkin, and Bhattacharya (2010) and Trolian, Jach, Hanson, and Pascarella (2016) made the connection between faculty-student interactions and motivation. Martin, Galentino, and Townsend (2014) linked motivation to retention. In their quantitative study of faculty-student interaction from the student's perspective, Komarraju, et al. (2010) sought to understand the value of these interactions and their impact on students' lives. They noted that faculty can have a long-lasting effect on their students, even though they may not be aware of it. Komarraju, et al. (2010) concluded that students who felt respected by, able to approach, and the confidence to interact frequently with their instructors outside of class were more likely to identify themselves as motivated and academically confident. Students who felt that their instructors were approachable were more comfortable seeking them out to discuss classwork and grades.

Trolian et al. (2016) arrived at a similar conclusion. They considered five measures of student-faculty interactions: quality and frequency of faculty contact, out-of-class, research, and personal discussions with faculty. They found all five to be positively correlated with academic motivation. In a model that considered all five variables, quality of faculty contact and frequency of faculty contact were found to be statistically significant.

Studies have shown that faculty-student interactions can lead to retention. Using a sample of 111 students in an introductory business course at a small private college, Lillis (2011) considered faculty-student interactions through the lens of faculty emotional intelligence, more 
simply described as faculties' people skills. They concluded that faculty are very influential in acclimating a student to his or her institution. Lillis (2011) suggested that instead of focusing only on students when trying to increase retention, instructors be provided with professional development to learn strategies to implement when mentoring students.

Student learning communities were first established in Kingsborough Community College, a two-year institution in the State University of New York system (Bonet \& Walters, 2016). In this model, developmental students attend classes in a cohort in which both developmental and non-developmental course instructors collaborate on integration of course content. Each cohort is provided with a mentor who also attends classes. Students in a learning community have more opportunity for individualized faculty-student interactions. Bonet and Walters (2016) concluded that students in learning communities are more likely to stay in college than developmental students in conventional classes. Wirt and Jaeger (2014) also noted that learning communities, as well as participation in orientation sessions, lead to student retention. They further suggested that since such a large percentage of community college faculty members' time on campus is devoted to being in direct contact with students, it makes sense for faculty, as opposed to other college personnel, to engage in interacting with students.

In addition to finding that students engaged in faculty-student interactions via learning communities are more likely to be retained, not surprisingly, Bonet and Walters (2016) concluded that these students attain better grades than developmental students not in learning communities. Grantham, Robinson, and Chapman (2015) also concluded that facultyinteractions lead to better grades. In their qualitative study at a four-year institution, they studied notes that students wrote to their instructors in a Thank-A-Teacher program. One theme discovered was that by meeting one-on-one with a faculty member, grades were improved two 
possible ways. First, the student has the opportunity to explain the work done on an exam, and the instructor may understand better the student's train of thought and award credit. Second, by meeting with an instructor, more one-on-one learning time takes place, which leads to better grades.

There are many benefits to interaction between faculty and students. Kimbark, Peters, and Richardson (2017) offered a suggestion that is of interest for the current study. They posited that interaction with students might be the solution to the struggle most institutions of higher learning experience with retention of students. A qualitative study of undergraduate and graduate students was performed by Pattison, Hale, and Gowens (2011) which solicited student responses concerning respectful and disrespectful faculty-student interactions. Based on their findings, they made the following suggestion: "... students are more likely to be satisfied and successful in classes where they perceive that their professors primarily care about them as individuals rather than merely concentrate on the transfer of knowledge as the most important criteria in teaching" (p. 63).

\section{Student-Student Interaction}

Just as interactions between faculty and students foster positive outcomes for students, such as better grades, motivation, sense of belonging and retention, so do student-to-student interactions. Tinto (2017) and Skari (2014) both discussed the effect of peer interactions on sense of belonging. Although Tinto (2017) referred to student persistence in universities, as stated earlier, Karp, Hughes, and O'Gara (2010) have validated that his work is effectively applicable to students at community colleges. Tinto (2017) gave two broad examples of opportunities for peer interaction that nurture a sense of belonging. The first is the small community of students who spend time together because of a similar interest such as a club or 
academic program. The second refers to the bonds that students form because of similar backgrounds, such as high school or ethnicity.

Skari (2014) studied alumni who donate to their community college alma maters. She found that graduates who gave donations were those who bonded with their institution by engaging in activities outside the classroom. These were the students who built relationships, were successful academically, persisted, and attained a degree. Sense of belonging is addressed as a construct later.

A study by Bonet and Walters (2016) linked student-to-student interaction with retention. In their study about learning communities, Bonet and Walters (2016) compared students in learning communities at Kingsborough Community College in New York City with students in the same college and same course who were not in learning communities. One of the three pillars of this pedagogical approach to instruction was "peer communication and teamwork" (p. 231). Together with the other two pillars, curriculum design and interactions between faculty and students, the important concept of students engaging with each other contributed to the success of learning communities. Students in this experimental group had better attendance which led to better grades, and ultimately higher retention rates. Bonet and Walters (2016) noted that persistence is a challenge particularly for community college students who do not live on campus. The opportunity for these students to engage with others facilitates persistence and progress.

Peck (2011) described a highly successful, unique peer advising program that was established at Stephen F. Austin State University in Texas. Although the program took place at a university, leaders at this institution saw the need to focus on retention, particularly of firstgeneration students. Since this population is characteristic of many community college students, 
this article was of interest for the current study. The program described by Peck (2011) was different from typical peer advisor programs because the student advisors discussed much more than academics with the first-semester students who came to see them. The advisors inquired about the freshmen's interests and guided them to an area of the college in which they could become involved. Further, new students were encouraged to ask any other questions related to the institution.

Data collected by Peck (2011) were promising: $91 \%$ and $82 \%$ of the advisees stated they felt more connected to the college and were likely to seek a leadership position in the future, respectively. Further, $95 \%$ of students who participated in the program re-enrolled for the Spring semester; that percentage is $86 \%$ for those who did not participate. These data indicated that student-to-student interaction can increase retention.

\section{Sense of Belonging}

A review of the literature related to student retention revealed several references to sense of belonging, including as it relates to adjusting to a large institutional environment (Bippus et al., 2001), increasing motivation of students (O'Riordan \& Broughton, 2017), and being a benefit of student cohorts (Bonet \& Walters, 2016). Sense of belonging is a mediating variable between interaction and retention, as illustrated by O'Keeffe (2013) and Tinto (2017).

O'Riordan and Broughton (2017) did a mixed methods study to evaluate an early intervention program aimed at providing first-year law students with a sense of belonging. By being engaged, these students felt cared for. Additionally, they felt comfortable asking questions because they knew someone was listening to them. As a result, they felt more motivated and set academic goals for themselves. 
O'Keeffe (2013) identified a sense of belonging to be critical, especially for students who are disconnected: working part-time, taking online classes, or rushing home to take care of family members. He also identified characteristics of students at risk of not persisting: low socioeconomic status, first-generation students, and ethnic minorities. Although his focus was on retention at four-year institutions, the characteristics he described are precisely those of community college students (Karp et al., 2010; Shannon et al., 2006, \& Wirt \& Jaeger, 2014).

As mentioned earlier, according to Tinto (2017), there are two types of sense of belonging. The first is belonging to a small community such as a club, cohort, or class; the second is feeling connected to the larger community, the institution. He stated that both lead to persistence, but the latter sense of belonging is more likely to lead to the persistence of students because small communities have the potential to feel isolated from the college at large.

It is worth noting that when students do not feel as if they belong, they are likely to drop out. Tinto (2017) stated that this "sense of not belonging, of being out of place, leads to a withdrawal from contact with others that further undermines motivation to persist" (p. 4). O'Riordan and Broughton (2017) concurred and described students who do not feel as if they belong as having feelings of isolation and disconnection, factors that contribute to student attrition.

\section{Retention}

One factor found in the literature that relates directly to student persistence is grades. Gershenfeld, Hood, and Zhan (2016) focused on the first-semester grade point averages (GPAs) of underrepresented students at a large university in the Midwest. A requirement of a student in the sample was that s/he was enrolled in at least one of three programs focused on student success. Admission into these programs had certain requirements; one was need-based, one was 
merit-based, and the third offered resources for students from under-resourced school districts. Using logistic regression, Gershenfeld et al. (2016) found the independent variable first-semester GPA was statistically significant as an indicator of graduation of underrepresented students. Specifically, these students who had a first-semester GPA of 2.33 or lower were about half as likely to graduate in six years as students with a higher first-semester GPA.

In a study of community college students, Bonet and Walters (2016) found similar results. In their study, they compared students in a learning community with students in traditional classes. They concluded that the experimental group had better grades and higher retention rates. In an older, but important study for the current research, Fike and Fike (2008) studied retention of first-time-in-college students at a community college in Texas.

Developmental education students were a specific focus of this study. Fike and Fike (2008) found, not surprisingly, that students who did not place into developmental coursework, as well as developmental students who passed those courses in their first year, were more likely to be retained both from first fall to first spring and from first to second fall semesters.

Motivation was a mediating variable of sense of belonging, student interaction with faculty, and moderate physical activity with retention. Tinto (2017) described students who have a sense of belonging to a small community or the institution as being motivated to persist in their college studies. Martin et al. (2014) linked motivation of community college students to graduation. In their qualitative study, Martin et al. (2014) interviewed graduates and employees of a large community college in the Southeastern United States. They concluded that there were four commonalities among community college graduates; one was strong motivation and a drive toward success. The others were self-empowerment, the ability to manage demands outside of school, and clear goals. 
Returning to the conceptual framework, this review of the literature addressed every relationship between constructs as indicated on the arrows in Figure 4 below.

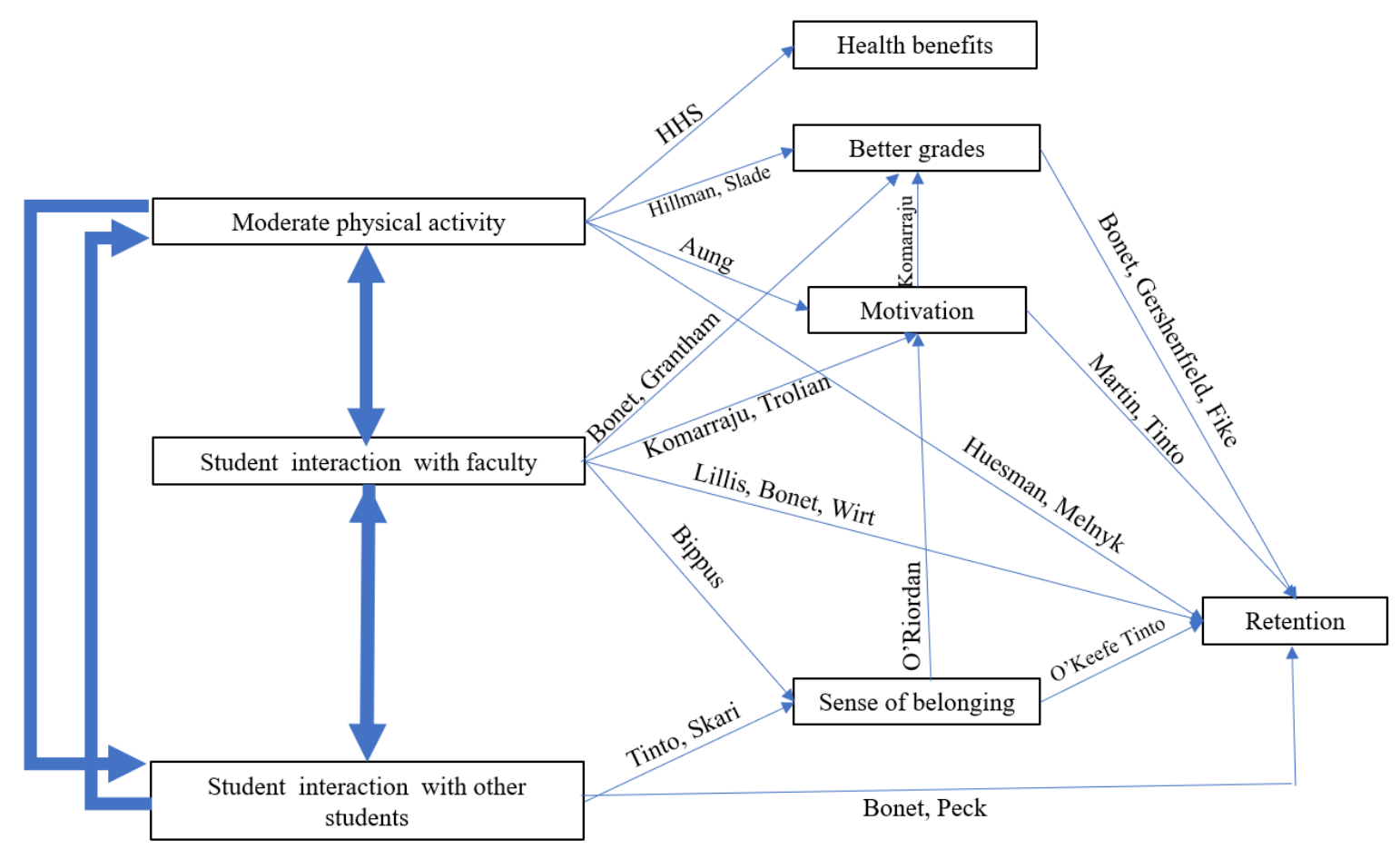

Figure 4. Conceptual framework for the current study with sources

The potential benefits of college personnel interaction with students should not be underestimated. Literature from decades ago and through current research confirmed this claim. Beal and Noel (1980) did an extensive study of 947 two- and four-year institutions and found that, by far, the most important factor in retaining students was a "caring attitude of faculty and staff" (p. 43). Pascarella and Terenzini (1979) concluded that one of the most important reasons that students are retained and persist, and therefore succeed, was interaction with faculty, both inside and outside the classroom. Students seek time with their instructors for more than just academic questions and advice; they want to discuss their careers, campus issues, current events, their personal lives, and simply socialize informally (McClenney \& Arnsparger, 2012; Pascarella \& Terenzini, 2005). 
Developing interpersonal relationships through student-faculty interaction leads to multiple positive student outcomes including retention and persistence (Pascarella \& Terenzini, 2005) and academic achievement and critical thinking (Tinto, 1993). However, there are barriers to these important relationships. Community college students of today often have family and financial responsibilities, leaving little time to spend on campus outside of the classroom. Another barrier to students is the perception that their instructors are too busy and therefore not interested in interacting with them (McClenney \& Arnsparger, 2012).

Lundberg and Schreiner (2004) noted another obstacle to interactions between faculty and students is the perspective of some faculty, who feel constrained by time and a sense that there is a lack of institutional support for interactions with students outside the classroom. However, some instructors understand the positive effects of establishing a rapport with their students and feel it is their responsibility to engage in that way (Lundberg \& Schreiner, 2004). These faculty members understand that interaction outside the classroom can lead to increased student motivation and attendance in their classes as well as better communication with students, in person and via email. (Benson, Cohen, \& Buskist, 2005).

It is clear that connections between students and faculty and staff are powerful motivators for students and result in their persistence and success at community colleges (Phillips, 2020; Tinto, 1993). In order to support the creation of these important connections that support student persistence and retention, community college leaders must be creative and intentional in finding ways to provide such opportunities for faculty, staff and students. A walking program that is flexible with time and space, as proposed in the current study, is one such opportunity; it is easy to implement and requires a very minimal financial investment. 
The current study examined whether a combination of moderate physical exercise and interaction with students by both peers and non-students will result in a greater likelihood of student retention. The results of the current study, together with potential positive results of future research at a larger scale, can inform community college leaders about a tool to increase student retention with very little cost and great benefits.

\section{Methodologies in Similar Studies}

In their study of medical students' time spent exercising and its relationship to academic motivation, Aung, Somboonwong, Jaroonvanichkul, and Wannakrairot (2016) used both univariable and multivariable regression. There were several independent variables including amounts of time spent sitting, sleeping, and exercising per day. The independent variable was intrinsic academic motivation as measured by a standardized, internationally validated Likert scale called the Academic Motivation Scale (AMS). The time students spent in physical exercise and the level of intrinsic motivation were significantly related in both the univariable and multivariable regression models. The population of the Aung, et al. (2016) study and the current study are quite different, but of concern here is the methodological approach of a similar study.

Huesman, Brown, Lee, Kellogg, and Radcliffe (2009) studied student success, in particular first-year retention and five-year graduation rates at a university, as it related to use of Campus Recreation Facilities (CRFs). Students gained access to CRFs by scanning college identification cards which afforded researchers easy access to student grades, registration status, etc. Since the dependent variables first-year retention and five-year graduation are dichotomous, logistic regression was used, which was the planned methodology to study the effects of number of minutes walked and number of people spoken to on retention in the current study. 
Concerning faculty-student interactions, Komarraju, Musulkin, and Bhattacharya (2010) studied undergraduate students at a mid-sized public university in the United States. The quantitative study used a survey to collect data about faculty-student interaction, academic motivation, and academic self-concept. Analyses were done using correlation and regression analysis. For the regression models, several variables related to faculty-student interaction were the predictors, and the dependent variables were various measures of student success.

Kimbark, Peters, and Richardson (2017) studied the effects of a student success course (SSC) on persistence at a community college in Texas. Part of their mixed-methods study involved a cross-tabulation of persistence data from a group of students who completed the SSC and a matched sample of those who did not. Using these two groups of students, Kimbark, et al. (2017) used a Chi Square Test of Independence and concluded that students in the SSC were significantly more likely to persist $(p<0.005)$.

It is clear from the literature that in studies similar to the current one, quantitative designs are appropriate. Specifically, the Chi Square Test of Independence was used in the case of a comparison group, which the first research question in the current study addresses. The second and third research questions are concerned with the extent that one variable affects a dichotomous variable. Ideally, these two questions could be condensed to one and logistic regression would be used. The results in Chapter Four discuss why that methodology could not be used as originally planned. Academic texts confirm the use of Chi Square tests (Sprinthall, 2012; Triola, 2019) and logistic regression (Diez, Barr, \& Cetinkaya-Rundel, 2014) for research similar to the current study.

The following chapters present a research design, data analyses, and findings that address the specific gap described in the literature review. Chapter 3 focuses on the methodologies to be 
used to answer the research questions. The results of the study are detailed in Chapter 4. Last, Chapter 5 concludes with a discussion of the results, implications of the findings, and suggestions for future research for practitioners and researchers in higher education. 


\section{CHAPTER 3}

\section{Methods}

This chapter describes in detail the research design, setting of the study, sampling method, and data collection method. A rationale for why the design and methods were chosen is presented. A discussion of how the collected data were analyzed as well as the bias of the study conclude this chapter.

\section{Problem Statement}

Student retention is a national concern for community colleges. Evidence of this concern includes a large body of literature that addresses this issue, including Gershenfeld, Hood, and Zhan (2016), Kimbark, Peters, and Richardson (2018), and Melnyk, Kelly, Jacobson, Arcoleo, and Shaibi (2014). Further indication of the concern surrounding student retention is the implementation and growth of performance-based funding, an initiative used by states that ties funding to college metrics which include retention rates (McKinney \& Hagedorn, 2017; Romano \& Palmer, 2016).

Research has shown that student interaction yields significant benefits for students in several areas. Specifically, student interaction with peers increases students' sense of belonging and leads to retention (Peck, 2011; Skari, 2014; Tinto, 2017). Additionally, the literature is abundant with studies that link student-faculty interaction to better grades (Bonet \& Walters, 2016; Grantham, et al., 2015), motivation (Komarraju, et al., 2010; Trolian, et al., 2016), sense of belonging (Bippus, et al., 2001), and retention (Bonet \& Walters, 2016; Wirt \& Jaeger, 2014).

The United States Department of Health and Human Services (2018) stated that "regular physical activity is one of the most important things Americans can do to improve their health" (p. 1). Research has shown that moderate physical activity has specific benefits for students. 
Hillman, et al. (2008) and Slade and Kies (2015) tied moderate physical activity to better grades. Further, moderate physical activity was shown to be linked to motivation (Aung, et al., 2016) and student retention (Huesman, et al., 2009; Melnyk, et al., 2014).

\section{Research Questions}

1. Is there a relationship between participation in the walking program and retention?

2. Are the number of minutes walked associated with retention for the semester following the walking program?

3. Are the number of people spoken to while walking associated with retention for the semester following the walking program?

\section{Research Design}

The current study used a quantitative methodology. The first research question considered the difference between the students in the walking program and a control group of matched students who did not participate. Addressing this question constituted a causal comparative design.

Students in the program were recruited via social media, signs and fliers on campus, orientation, and in classrooms. Any student who did not transfer or graduate in December of 2019 and entered at least one data value in their Google sheet was considered in the sample for the research study. At the conclusion of the Fall 2019 semester, via college records in the Office of Institutional Research, subjects in the sample were matched with a random sample of nonwalking students on the basis of age category, ethnicity, gender, semester in Suburban, and Pell eligibility to create a control group. Students in the matched sample could not have graduated nor transferred at the end of the Fall 2019 semester. 
The final data collected were the values for the dependent variable, "retention" (RET). If a student enrolled in Suburban for the Spring 2020 semester, the variable RET took on the value 1. Otherwise, the variable was 0 . Once all data were collected, in order to see if there was a significant difference in retention between members of the walking program and their matched pairs, a Chi Square Test of Independence was conducted.

The second and third research questions were concerned about the extent to which students participated in the walking program, the number of people they spoke to, and whether or not they were retained in college. The two questions were addressed using the independent variables "total number of minutes walked" and "number of people spoken to," respectively, and the dependent variable "retention." Ideally, since RET is dichotomous, these two research questions could be combined into one, and logistic regression could be used. In the case of the present study, since the sample size was not sufficient to use logistic regression, the Fisher's Exact Test was used for the second and third research questions (Kim, 2017).

\section{Setting of the Study}

Suburban Community College is a mid-sized two-year institution in the northeastern United States with a Fall 2019 enrollment of 4,891 students, which included 46.2\% part- and $53.8 \%$ full-time students. There is one main campus at which $75 \%$ of the student population primarily attend. The other $25 \%$ take most classes at the single branch campus, approximately 30 miles away from the main campus. About $24 \%$ and $60 \%$ of the student population are firsttime and continuing students, respectively. The remaining students are transfer, returning, or auditors (Suburban Community College website). At Suburban Community College, the fall-tofall retention rate for the 2017 cohort of first-time, full-time students was $63 \%$. For part-time students in the same cohort, the retention rate was $47 \%$ (NCES, 2018). 
Suburban Community College is a Hispanic Serving Institution with $29.6 \%$ of students self-identifying as Hispanic or Latino/a. 46.8\% are White, $13.9 \%$ are Black, and there are very few students who identify as Asian, American Indian, Alaskan Native, Natural Hawaiian, or Pacific Islander. Students are predominantly female; $59.2 \%$ are female and $40.5 \%$ are male. Approximately four-fifths of the students are between the ages of 18 and 29 and $35.3 \%$ of all students are 18 or 19 years of age. Suburban has seen a steady decline in enrollment since 2011.

The college is situated in a mid-Atlantic state, with each of the two campuses located in an urban area, surrounded by suburbs. There are no residence halls, so many students come to campus to take classes and then depart. Suburban has the following athletic programs: men's and women's basketball, men's and women's cross country, softball, baseball, men's golf, and women's volleyball. There are multiple physical education courses available, but these courses are not required for most programs. One of the classes available is a walking course, "Walking for Wellness." In the Fall 2019 semester, three sections of this course ran, two on the main campus, and one on the branch campus, for a total of 64 students. Students in these classes were specifically invited to join the program, but their participation was voluntary.

Each campus has a central grassed-in area ("The Green") surrounded by instructional and administrative buildings. They are ideal places for walking and conversation. For those who wished to expand their walking paths, each campus could be traversed on the outer border of its buildings. In case of inclement weather, there were indoor opportunities on each campus for walking. There is no indoor track, but several buildings are connected, and walking program participants were able to alternate between traversing extended halls and staircases. Students were also able to enter data for walking off campus. 


\section{Sampling Method and Data Collection}

The population for this study was all students at Suburban Community College. In order to be part of the sample, a student had to decide for him- or herself to join the walking program. As a result of this restriction, it was impossible to use random selection for the sample, and therefore the probability of a student being selected to be in the sample cannot be determined. Therefore, there was no choice but to use convenience sampling for the current study (Leedy \& Ormrod, 2016).

Prior to the beginning of the data collection process, approval was received from the Old Dominion University (ODU) College of Education Human Subjects Committee. A copy of the approval letter can be found in Appendix H. Following the ODU approval, the same application process occurred at Suburban Community College. A copy of this approval letter is in Appendix I.

After both approvals for exempt research were attained, the following recruiting efforts were made. All new students are required to attend an in-person orientation session at which a flier was distributed, along with a verbal announcement. The flier is attached as Appendix D. Identical fliers were posted on college bulletin boards, both physical and electronic. Five days before the start of the Fall 2019 term, a college assembly meeting was held. This was a wellattended meeting that included administration, faculty, and staff from the college. During this meeting, the researcher described the current study, the walking program, and encouraged all to participate, emphasizing that college personnel were being asked not only to walk, but additionally to engage students in conversation. Faculty were asked to announce the program on the first day of class and encourage students to participate either alone or with others. 
In order to join, students and college personnel needed only to emailwalk@suburban.edu from a Suburban Community College email address and express their interest in walking. Every participating student received an email from the researcher (Appendix G) and was provided with a Google sheet (Appendix A) shared only between the student and researcher. By filling out the information on the Google sheet, the students acknowledged that they had read the email and agreed to participate in the program. Similarly, college personnel who joined the program received a simpler Google sheet (Appendix B), also shared only between the employee and the researcher.

The following demographic data was entered by each student walking program participant: student id \# "ID," gender "GEN," age "AGE," whether or not they think they are Pell eligible (yes or no) "PELL," and student's current semester (first, second, etc.) "SEM." Other data collected but not used for analysis were name, primary campus, whether or not a student intended to graduate or transfer at the end of the Fall 2019 semester, and whether or not a student was a member of the college Bridges program. The Bridges program is a college experience program for students with special needs. It is an opportunity for these students to have a college experience, but the enrollment practices and tuition are very different from those of traditional students. Students who planned to graduate or transfer at the end of the Fall semester and students in the Bridges program were welcome to walk but were excluded from the sample.

Each day a student walked, he or she made 3 entries for that day: the number of minutes walked "NMW," the number of people spoken to "NPS," and the location of the walk "LOC." There were two choices for LOC: on/near campus and off campus. The student Google sheet also contained formulas to calculate the cumulative NMW and, using a walking rate of 20 minutes per mile (Hoeger et al., 2008), calculated the cumulative number of miles walked 
"NMiW." The column NPS was totaled automatically. The "number of days walked," NDW was also noted for each student. As an incentive to reach milestones, each sheet contained a line graph showing the cumulative number of miles walked so that students were able to visually track their progress. A summary of the variables in the current study is found in Table 1. 
Table 1

Variables in Study

\begin{tabular}{ll}
\hline Variable & Meaning \\
\hline ID & Student identification number \\
AGE & Gender \\
ETH & Age \\
PELL & Student's ethnicity \\
SEM & Perceived Pell eligibility (yes/no) \\
NMW & Student's current semester \\
NPS & Number of minutes walked \\
LOC & Number of people spoken to while walking \\
NMiW & Location of walk \\
NDW & Number of miles walked \\
RET & Number of days walked \\
\hline
\end{tabular}

Interested college personnel also emailed walk@suburban.edu. In return they received an email encouraging them to invite students to participate and to engage in conversation with student walkers. They were given the following suggested prompts: "Hi, I am Ms. X; I work in the Psychology department." "What are you studying?" "How has your experience at Suburban been?" "Is there anything I can help you with?" Additionally, the email contained this suggestion: "If students need to go to an office, walk them there if you can!" Non-students had a slightly different Google sheet (Appendix B). No demographic data were collected. They 
entered the number of minutes walked and number of students spoken to per day and had the same line graph showing the cumulative number of miles walked. The purpose of collecting employee data was simply as a motivation for them to continue participation in the program. Both students and non-students who reached 10, 25, or 50 miles were acknowledged by having their names posted on a banner located in a prominent place, one on each campus (Appendix E).

The walking program ran from the first day of classes until the last day of finals. Upon the completion of the program, the data from all student Google sheets were aggregated into one Excel spreadsheet (Appendix C), to which only the researcher had access, which contained the following entries for each participant: student participant number, identification number, total number of minutes walked, total number people spoken with, total number of days walked, and whether or not the student enrolled at Suburban Community College for the Spring 2020 semester. Having the data in matrix form made exporting into SPSS for the data analyses seamless.

\section{Data Analyses}

First, descriptive data were presented to summarize the results; then the research questions were addressed. The descriptive data summarized the demographic information reported by the students: gender, age, semester enrolled at Suburban Community College, ethnicity and perceived Pell-eligibility as well as the number of days walked. GEN, AGE, ETH, PELL, and SEM are categorical data and therefore were summarized in tables in Chapter 4. The means and standard deviations were calculated for the ratio variables; NMiW, NPS, and NDW, and presented in Chapter 4. Presentation of these data in such forms gives the reader a quick understanding of who participated. A comparison could be made to national data that describe community college students. According to the American Association of Community Colleges 
(2020), credit bearing community college students were $57 \%$ female and $43 \%$ male; $26 \%$ Hispanic, $13 \%$ black, $45 \%$ white, $6 \%$ Asian or Pacific Islander, and 11\% other. Fifty-four percent were 22 years old or younger, $38 \%$ were between 22 and 39 , and $9 \%$ were over 40 . Thirty-three percent of students receive Pell grants.

The first research question concerned comparing retention rates of students in the walking program with a control group of students, matched by demographic data. To address this question, a Chi-Squared Test for Independence was performed (Triola, 2019). The alpha level was set at .05 and there was one degree of freedom. Therefore, the critical value was 3.84 . The null hypothesis was: There is no relationship between retention and participation of students in the walking program. This chi square test is the appropriate hypothesis test because it is used for testing the independence of two nominal variables.

Logistic regression analyses were planned to address the original second research question, which addressed the effect certain independent variables have on retention, a binary dependent variable. Students who were retained were coded as "1" and students who were not were coded as "0." Since there needed to be 100 or more participants in order to use logistic regression, and there were only 69 , another method needed to be used, which required separating the original second research question into two: the second and third research questions presented in this study. Since both NMW and NPS were able to be defensibly dichotomized, the Fisher's Exact Test was used for the analysis of the second and third research questions.

\section{Bias}

The researcher of the current study is the supervisor of some chairs and faculty who were encouraged to participate in the program and interact with students. There may have been bias 
due to the unintentional authoritative relationship between the researcher and faculty participants. 


\section{CHAPTER 4}

\section{Results}

The purpose of this study was to explore the effect of a voluntary walking program that combined moderate physical activity, student interaction with peers, and student interaction with college faculty, staff, and administrators, on student retention at a community college. Results from studies in the literature indicated that, separately, moderate physical activity (Huesman, Brown, Lee, Kellogg, \& Radcliffe, 2009; Melnyk, Kelly, Jacobson, Arcoleo, \& Shaibi, 2014), student interaction with other students (Bonet \& Walters, 2016; Peck, 2011), and student-faculty interaction (Lillis, 2011; Wirt \& Jaeger, 2014) can lead directly to student retention. Other studies conclude that these same three constructs lead indirectly to retention through mediating variables. These variables include better grades (Hillman, Erickson, \& Kramer, 2008; Grantham, Robinson, \& Chapman, 2015), motivation (Aung, Somboonwong, Jaroonvanichkul, \& Wannakrairot, 2016; Komarraju, Musulkin, \& Bhattacharya, 2010), and sense of belonging (Bippus, Kearney, Plax, \& Brooks, 2003; Tinto, 1973). The intention of the walking program study was to combine student interaction and physical activity to determine if the combination of these constructs increase student retention at a community college. The current study was guided by the following research questions.

\section{Research Questions}

1. Is there a relationship between participation in the walking program and retention?

2. Are the number of minutes walked associated with retention for the semester following the walking program?

3. Are the number of people spoken to while walking associated with retention for the semester following the walking program? 
Prior to presenting the statistical results, a short discussion about the study participants and the process of data collection along with the implementation of the walking program are presented. The statistical results were organized into three categories. First, descriptive statistics were compiled and analyzed. Next, a Chi Square Test of Independence was conducted to compare the sample of program participants with a matched sample of students who did not participate; this analysis constituted a causal comparative design. Finally, since the sample size was less than 100, the planned logistic regression could not be used to determine the extent to which the number of minutes walked, the number of people spoken to while walking, or both, predict the likelihood that participants enrolled in at least one class in the subsequent semester (Spring 2020). Instead, two separate Fisher's Exact Tests were conducted, considering (1) the independence of the number of minutes walked and retention and (2) the independence of the number of people spoken to and retention.

\section{Participants}

One hundred nineteen students signed up to participate in the walking program. The researcher, with the assistance of Suburban Community College's Office of Institutional Research, was able to identify students who were not eligible for the study. Reasons for ineligibility included: graduated or transferred to another institution following the Fall 2019 semester, participation in the College's Bridges program (a college-experience program for disabled students in which students do not follow the traditional schedule, payment plan, etc.), high school students taking classes on campus, and participants under the age of 18 . Ultimately, 69 student walkers were eligible for the study. 


\section{Data Collection}

In the summer and weeks prior to the start of the Suburban Walks! Program, the researcher advertised as planned; over 100 non-students signed up before classes began. During the first week of classes in the Fall 2019 semester, student enrollment in the program was sluggish, so the researcher sought and was granted permission to speak in Mathematics classes to encourage student participation. Since students in all programs are required to take some level of Math, speaking to students in a variety of these courses allowed for a broad audience. All instructors encouraged student participation. Some instructors offered modest academic incentives, such as a single point on an exam.

The researcher aimed for a sample size of 100 student walkers in order to use logistic regression for the original second research question. Therefore, every student who signed up for the program and participated at least once was considered part of the study. Although 119 students signed up, some never walked, some were graduating or transferring, and some belonged to the Bridges program. The final sample size was 69.

The weather was very conducive for walking outdoors right up until November 1, which was helpful to the success of the study. Enthusiasm by non-students was high at the beginning of the term and waned for many as the semester progressed. Student commitment to walking was varied. Table 2 is a frequency distribution illustrating the number of days walked by students. As the weather became cold, many students walked less; some even stopped walking completely. Since students were permitted to walk indoors or off campus, it was understandable that some continued their participation in the program until the very end of the semester. 
Table 2

Frequency Distribution of Number of Days Walked

\begin{tabular}{cc}
\hline Number of Days Walked & Frequency \\
\hline under 10 & 22 \\
$10-19$ & 9 \\
$20-29$ & 7 \\
$30-39$ & 8 \\
$40-49$ & 4 \\
$50-59$ & 15 \\
$60-69$ & 1 \\
$70-75$ & 3 \\
\hline
\end{tabular}

At the conclusion of the Fall 2019 semester, the walking program was officially over and the Suburban College Office of Institutional Research was able to run a report that enabled the researcher to attain a matched sample. Initially, the report was expected to list every student enrolled at the college with their age, ethnicity, gender, semester at Suburban, and Pell eligibility (yes/no). All of these variables were available except the semester. In order to find the semester of each individual, the researcher would have needed to search over 4000 student records; therefore, the decision was made to eliminate this variable for matching samples.

A matched sample was attained by first categorizing all participants in a frequency table by GEN, ETH, PELL (measured by students indicating if they thought they were eligible for financial aid), and AGE. Table 3 summarizes this information. 
Table 3

Demographics of Sample

\begin{tabular}{lllll}
\hline Gender & Ethnicity & $\begin{array}{l}\text { Think Fin } \\
\text { Aid? }\end{array}$ & Age & Frequency \\
\hline Female & African-American & no & over 30 & 1 \\
Female & Asian & no & $18-20$ & 1 \\
Female & Asian & yes & $21-25$ & 1 \\
Female & Caucasian & no & $18-20$ & 5 \\
Female & Caucasian & no & $21-25$ & 1 \\
Female & Caucasian & yes & $18-20$ & 13 \\
Female & Caucasian & yes & $26-30$ & 2 \\
Female & Caucasian & yes & over 30 & 2 \\
Female & Hispanic & no & $18-20$ & 3 \\
Female & Hispanic & no & $21-25$ & 1 \\
Female & Hispanic & yes & $18-20$ & 4 \\
Female & Hispanic & yes & $21-25$ & 2 \\
Female & Hispanic & yes & $26-30$ & 1 \\
Female & Other & no & $18-20$ & 1 \\
Female & Other & yes & $18-20$ & 3 \\
Female & Other & yes & over 30 & 1 \\
Male & African-American & yes & $18-20$ & 1 \\
Male & Asian & yes & $18-20$ & 2 \\
Male & Asian & yes & $21-25$ & 1 \\
Male & Caucasian & no & $18-20$ & 1 \\
Male & Caucasian & yes & $18-20$ & 6 \\
Male & Caucasian & yes & $21-25$ & 1 \\
Male & Caucasian & yes & over 30 & 1 \\
Male & Hispanic & no & $18-20$ & 2 \\
Male & Hispanic & no & $21-25$ & 1 \\
Male & Hispanic & yes & $18-20$ & 4 \\
Male & Hispanic & yes & $21-25$ & 4 \\
Male & Hispanic & yes & $26-30$ & 1 \\
Male & Other & no & $26-30$ & 1 \\
Male & Other & yes & over 30 & 1 \\
\hline & & & & \\
\hline
\end{tabular}

Next, each row of Table 3 was given a code; there were 45 codes. The report from the Office of Institutional Research, which contained 4,329 rows, was then sorted in the same order as in Table 3. That is, first by GEN, then by ETH, PELL, and AGE. For sorting purposes, the 
categorization shown in Table 4 was used for age groups. Finally, using a random number generator, a matched sample of 69 non-student participants was attained.

Table 4

Categorization for Age Groups

\begin{tabular}{cc}
\hline Age & Age Category \\
\hline $18-20$ & 1 \\
$21-25$ & 2 \\
$26-30$ & 3 \\
$>30$ & 4 \\
\hline
\end{tabular}

\section{Descriptive Statistics}

Once the walking program was over, the data were aggregated, and some student participants were removed from the study. Two had dropped out of the college mid-semester, one was in a high-school program on campus, and one was in the Bridges program, a college experience program for disabled students who use a tuition and attendance protocol very different from the main college. Two others indicated their intention to transfer or graduate at the end of the Fall 2019 semester.

The enrollment freeze date for Spring 2020 was February 4. Until that time, it could not be accurately determined who registered for the Spring semester. Therefore, before February 4, only descriptive statistics could be determined. These results are described in this section.

Age. As stated earlier, there were four categories from which students had to choose: 18-20, 21-25, 26-30, and over 30. As seen in Table 5, the overwhelming majority of participants were in the 18-20 age range, and 91\% were between the ages of 18 and 29 . Since approximately $80 \%$ of the students in the entire college are between the ages of 18 and 29 and 
$35 \%$ of all students are 18 or 19 (Suburban Community College website), the sample is heavily weighted in the $18-20$ age category.

Table 5

Age Distribution for Participants

\begin{tabular}{ccc}
\hline Age Range & Frequency & Percentage \\
\hline $18-20$ & 46 & $67 \%$ \\
$21-25$ & 12 & $17 \%$ \\
$26-30$ & 5 & $7 \%$ \\
over 30 & 6 & $9 \%$ \\
\hline
\end{tabular}

Gender. The percentages of females and males at Suburban for the Fall 2018 were $59.3 \%$ and $40.7 \%$, respectively. Table 6 illustrates the distribution of gender for the sample of walking participants. It is clear that there were more females than males, and the difference was slightly greater than that of the overall college population.

Table 6

Gender Distribution for Participants

\begin{tabular}{cccc}
\hline Gender & Frequency & Percentage & $\begin{array}{c}\text { Percentage for All } \\
\text { Students at SCC }\end{array}$ \\
\hline male & 27 & $39.1 \%$ & $40.70 \%$ \\
females & 42 & $60.9 \%$ & $59.30 \%$ \\
\hline
\end{tabular}

Semester. Each participating student chose from the following categories for the semester they were in during the Fall 2019: First, second, third, fourth, more than fourth. As indicated in Table 7, most students were in their first semester. This result is not surprising since such a large majority of the student sample was between 18 and 20 years old. 
Table 7

Semester Distribution for Participants

\begin{tabular}{ccc}
\hline Semester & Frequency & Percentage \\
\hline 1st & 35 & $51 \%$ \\
2nd & 6 & $9 \%$ \\
3rd & 13 & $19 \%$ \\
4th & 5 & $7 \%$ \\
more than 4th & 10 & $14 \%$ \\
\hline
\end{tabular}

Financial aid eligibility. Since asking students about their financial information is personal and may appear intrusive, the researcher had participants answer the question "Do you think you are eligible for financial aid?" Seventy-six percent of the sample believed they were eligible. College-wide, $36.7 \%$ of students were Pell-eligible, well below the percentage of perceived eligibility in the sample. This distribution is given in Table 8 .

Table 8

Financial Aid Distribution for Participants

\begin{tabular}{ccc}
\hline $\begin{array}{c}\text { Students Think Eligible } \\
\text { for Financial Aid? }\end{array}$ & Frequency & Percentage \\
\hline yes & 51 & $74 \%$ \\
no & 18 & $26 \%$ \\
\hline
\end{tabular}

Ethnicity. The distribution of the participants' ethnicities is given in Table 9 in order of highest to lowest percentages. The table also lists the college-wide ethnicity distribution for the Fall 2019 semester. Both the Caucasian and Hispanic populations have very similar percentages for both the study sample and the whole college; therefore, the sample is representative of the 
college population for these two ethnicities. In the remaining three categories, the samples are not representative of the college population.

Table 9

Ethnicities Distribution for Participants

\begin{tabular}{ccc}
\hline Ethnicity & $\begin{array}{c}\text { Percentage of } \\
\text { Sample }\end{array}$ & $\begin{array}{c}\text { Percentage of College } \\
\text { Population }\end{array}$ \\
\hline Caucasian & $46 \%$ & $47 \%$ \\
Hispanic & $33 \%$ & $30 \%$ \\
other & $10 \%$ & $7 \%$ \\
Asian & $7 \%$ & $2 \%$ \\
African-American & $3 \%$ & $14 \%$ \\
\hline
\end{tabular}

Means and Standard Deviations of Ratio Variables

Table 10 contains the means and standard deviations of the three ratio variables "number of minutes walked" (NMiW), "number of people spoken to" (NPS), and "number of days walked" (NDW). For all three variables, the standard deviations are quite large, indicating that the data values are very spread out. Eleven students walked over 100 miles; one reached 379. These values contributed to the spread of NMiW. Regarding the spread of NPS, 12 participants spoke to zero or one person, while one spoke to over 800; these extreme values contributed to the large standard deviation of 176.5 for NPS. 
Table 10

Means and Standard Deviations of Ratio Variables

\begin{tabular}{|c|c|c|}
\hline & Mean & $\begin{array}{c}\text { Standard } \\
\text { Deviation }\end{array}$ \\
\hline \# miles walked & 52.9 & 60.8 \\
\hline \# people spoken to & 95.5 & 176.5 \\
\hline \# days walked & 28 & 22.7 \\
\hline
\end{tabular}

\section{Research Question One}

The first research question was "Is there a relationship between participation in the walking program and retention?” A Chi-Squared Test of Independence was used in which the null hypothesis was: There is no relationship between retention and participation of students in the walking program. Table 11 shows the cross-tabulations grid with expected values, as it appeared in the IBM SPSS Statistics Viewer.

Table 11

Walker/Enroll Crosstabulation

\begin{tabular}{lcccc}
\hline & \multicolumn{2}{c}{ Enroll } & & Total \\
\cline { 2 - 3 } $\begin{array}{c}\text { Walker } \\
\text { no }\end{array}$ & & & \\
$\quad$ count & 13 & 56 & \\
$\quad$ expected & 7.5 & 61.5 & & 69 \\
$\quad$ yes & & & 69.0 \\
$\quad$ count & 2 & 67 & \\
$\quad$ expected & 7.5 & 61.5 & & 69.0 \\
Total & & & \\
$\quad$ count & 15 & 123 & \\
$\quad$ expected & 15.0 & 123.0 & & 138.0 \\
\hline
\end{tabular}


The results from SPSS gave a calculated value of Chi-Squared as 10.180, with a $p$-value of 0.003, as indicated in Table 12. Therefore, the results were significant, and the null hypothesis was rejected. There is strong evidence to suggest there is a relationship between participation in the walking program and re-enrolling in college.

Table 12

Chi-Squared Results for Research Question One

\begin{tabular}{cccccc}
\hline & Value & df & $\begin{array}{c}\text { Asymptotic } \\
\text { Significance } \\
\text { (2-sided) }\end{array}$ & $\begin{array}{c}\text { Exact Sig. } \\
\text { (2-sided) }\end{array}$ & $\begin{array}{c}\text { Exact Sig. } \\
\text { (1-sided) }\end{array}$ \\
\hline Pearson Chi-Square & $9.050^{\mathrm{a}}$ & 1 & 0.003 & & \\
Likelihood Ratio & 9.999 & 1 & 0.002 & & \\
Fisher's Exact Test & & & & 0.005 & 0.002 \\
N of Valid Cases & 138 & & & & \\
\hline
\end{tabular}

a. 0 cells $(0.0 \%)$ have expected count less than 5 . The minimum expected count is 7.50 .

\section{Research Question Two}

The second research question asked whether or not there was a relationship between NMW and retention. The method of data analysis originally planned to consider the effect of NMW, NPS, or both on retention was logistic regression. Due to the small sample size, Fisher's Exact Test was performed instead. The second research question considered the relationship between NMW and retention.

For Research Question Two, the null hypothesis was: There is no relationship between the number of minutes participants walked and retention. The American Heart Association (2018) recommends that adults should spend a minimum of 150 minutes per week engaging in moderate-intensity aerobic physical activity. This metric is equivalent to 21.4 minutes per day. 
Using 21.4 minutes as a cut-off value, the variable NMW was dichotomized and a crosstabulations table was created, as seen in Table 13.

Table 13

Number of Minutes per Day Walked / Enroll Crosstabulation

\begin{tabular}{ccccc}
\hline & \multicolumn{2}{c}{ Enroll } & & Total \\
\cline { 2 - 3 } \cline { 5 - 5 } & no & yes & & \\
\hline $\begin{array}{c}\text { Min/day }<21.4 \\
\text { count } \\
\quad \text { expected }\end{array}$ & 0 & 16 & & 16 \\
$\begin{array}{l}\text { Min/day 21.4 or more } \\
\quad \text { count }\end{array}$ & 0.5 & 15.5 & & 16.0 \\
$\quad$ expected & 1.5 & 51.5 & & 53.0 \\
Total & & & & \\
$\quad$ count & & & & \\
$\quad$ expected & 2.0 & 67.0 & & 69.0 \\
\hline
\end{tabular}

If all expected values were at least five, a Chi-Squared Test could be used. Since this is not the case, SPSS uses Fisher's Exact Test. As seen in Table 14, the resulting $p$-value was 0.587 , which does not indicate significance. Therefore, the null hypothesis was not rejected. There was insufficient evidence to suggest that there is a relationship between the number of minutes students walk per day and retention. 
Table 14

Chi-Squared Results for Research Question Two: NMW

\begin{tabular}{|c|c|c|c|c|c|}
\hline & Value & df & $\begin{array}{c}\text { Asymptotic } \\
\text { Significance } \\
\text { (2-sided) }\end{array}$ & $\begin{array}{l}\text { Exact Sig. } \\
\text { (2-sided) }\end{array}$ & $\begin{array}{l}\text { Exact Sig. } \\
\text { (1-sided) }\end{array}$ \\
\hline Pearson Chi-Square & $0.622^{\mathrm{a}}$ & 1 & 0.430 & & \\
\hline Likelihood Ratio & 1.073 & 1 & 0.300 & & \\
\hline Fisher's Exact Test & & & & 1.000 & 0.587 \\
\hline $\mathrm{N}$ of Valid Cases & 69 & & & & \\
\hline
\end{tabular}

a. 2 cells (50.0\%) have expected count less than 5 . The minimum expected count is .46 .

\section{Research Question Three}

The third research question considered NPS and retention. The null hypothesis was: There is no relationship between the number of people spoken to while walking and retention. The literature was clear that student interaction, whether with peers or faculty, measured in this study as NPS, positively influences a student's decision to stay in college (Bonet \& Walters, 2016, Lillis, 2011, Peck, 2011). Using zero people as a cut-off value, the variable NPS was dichotomized and a cross-tabulations table was created, as seen in Table 15. 
Table 15

NPS / Enroll Crosstabulation

\begin{tabular}{lcccc}
\hline & \multicolumn{2}{c}{ Enroll } & & Total \\
\cline { 2 - 3 } & no & yes & \\
\hline $\begin{array}{l}\text { Spoke to 0 people } \\
\text { count }\end{array}$ & 0 & 7 & 7 \\
$\quad$ expected & 2.0 & 6.8 & & 7.0 \\
Spoke to more than 0 people & & & \\
$\quad$ count & 2 & 60 & 62 \\
$\quad$ expected & 1.8 & 60.2 & & 62.0 \\
Total & & & \\
$\quad$ count & 2 & 67 & 69 \\
$\quad$ expected & 2.0 & 67.0 & 69.0 \\
\hline
\end{tabular}

Again, at least one cell has an expected value of less than five, so the Fisher's Exact Test was used by SPSS. As seen in Table 16, the resulting $p$-value was 0.806 , indicating no significance; the null hypothesis was not rejected. There was insufficient evidence to suggest that there is a relationship between the number of people spoken to while walking and retention.

Table 16

Chi-Squared Results for Research Question Three: NPS

\begin{tabular}{cccccc}
\hline & Value & df & $\begin{array}{c}\text { Asymptotic } \\
\text { Significance }(2- \\
\text { sided) }\end{array}$ & $\begin{array}{c}\text { Exact } \\
\text { Sig. } \\
\text { (2-sided) }\end{array}$ & $\begin{array}{c}\text { Exact } \\
\text { (1-sig. }\end{array}$ \\
\hline Pearson Chi-Square & $0.233^{\mathrm{a}}$ & 1 & 0.630 & & \\
Likelihood Ratio & 0.435 & 1 & 0.510 & & 0.806 \\
Fisher's Exact Test & & & & & \\
N of Valid Cases & 69 & & & & \\
\hline
\end{tabular}

a. 2 cells $(50.0 \%)$ have expected count less than 5 . The minimum expected count is .20 . 


\section{CHAPTER 5}

\section{Discussion}

Student persistence and retention are of great concern to community college leaders. According to the National Student Clearinghouse (2019), since the end of the recession in 2008 through 2016, the percentage of students who begin at community colleges and are retained from fall to fall lags below 50\%. Enrollment declines, state funding decreases, and performance-based funding increase the pressure on community colleges to retain students (McKinney \& Hagedorn, 2017; Romano \& Palmer, 2016).

Community college leaders have historically been committed to the mission of open access. This mission results in underprepared students, first-generation students, and those of low-socioeconomic status. Students from these circumstances are less likely than those in more stable financial situations to persist, be retained, and graduate (Schudde \& Goldrick-Rab, 2016). Often these students do not understand how to navigate college systems such as financial aid and study skills. Two factors that have been linked to retention are moderate physical activity (Huesman, Brown, Lee, Kellogg, \& Radcliffe, 2009; Melnyk, Kelly, Jacobson, Arcoleo, \& Shaibi, 2014) and student interaction (Bonet \& Walters, 2016; Peck, 2011; Tinto, 1993).

Unfortunately, community college students have fewer opportunities than their four-year college counterparts to become engaged in campus life. Community colleges have fewer residence halls and facilities that promote socialization such as sporting venues or game rooms. Many students are part-time, have family responsibilities, and/or work 20 or more hours per week, and therefore their time for participation in campus life activities is limited (Karp, Hughes, \& O'Gara, 2010). 


\section{Purpose Statement}

The purpose of this study was to explore the effect of a voluntary walking program that combined moderate physical activity, student interaction with peers, and student interaction with college faculty, staff, and administrators, on student retention at a community college. The current study was guided by the following three research questions.

\section{Research Questions}

1. Is there a relationship between participation in the walking program and retention?

2. Are the number of minutes walked associated with retention for the semester following the walking program?

3. Are the number of people spoken to while walking associated with retention for the semester following the walking program?

\section{Methodology}

The methodology for the current study was quantitative. Data were collected via Google sheets, one per participant (Appendix A). Each was shared only between the participant and the researcher. The sheet provided space for the participant to enter demographic data: gender, ethnicity, whether or not the student believed s/he was Pell-eligible, the student's current semester, and age. For each day of the Fall 2019 semester, each student entered the number of minutes s/he walked, number of people spoken to, and whether the walk was on/near campus or off. At the semester's end, the researcher summarized all data, removing those who did not meet the criteria of the study: students who signed up but did not participate, graduated or transferred in December of 2019, or took classes in an unusual way, such as high school students.

First, summaries of demographic data were presented: frequency distributions of number of days students walked; the thirty combinations of student demographics; frequencies and 
percentages of age range, semester, and Pell-eligibility; and a comparison of the distribution of participants' and college population genders and ethnicities. Next, the research questions were addressed. For Research Question One, the relationship of two nominal variables were considered. The appropriate test was a Chi-Squared test for Independence in which the null hypothesis was: There is no relationship between retention and participation of students in the walking program.

For the second and third research questions, two ratio variables," number of minutes walked" (NMW) and "number of people spoken to" (NPS) were to be considered as they contributed to retention, a binary variable. The best statistical approach would be logistic regression. However, for the current study, the minimum number of participants needed to be 100 in order to use that methodology. Therefore, a Fisher's Exact Test was used for each of those two variables as they separately related to retention, since this test is appropriate for small samples.

\section{Findings}

The descriptive statistics of participant demographics gave a snapshot of the 69-person sample. Twenty-two of the students in the sample walked under ten days; the next largest frequency for number of days walked was 50-59. Of the 45 combinations of gender, age category, perception of financial need, and ethnicity, the most common (29\%) were females between the ages of 18 and 20, who thought they were eligible for financial aid, and Caucasian. Two-thirds of the participating students were in the 18-20 age category. The ratio of female to male walkers was $3: 2$, almost exactly mirroring the true gender distribution of students at Suburban Community College. 
The percentage distribution for participants' first, second, third, fourth, or more than fourth semester at Suburban Community College was, respectively, 51\%, 9\%, 19\%, 7\%, and $14 \%$. Since it was a Fall semester during which the walking program took place, it is not surprising that $70 \%$ of the students were in their first or third semester. Almost three-fourths of the participants believed they were eligible for financial aid. Finally, the percentages of student walkers who were Hispanic or Caucasian closely represented the Suburban Community College populations. In the sample, $46 \%$ and $33 \%$ were Caucasian and Hispanic, respectfully. These percentages were $47 \%$ and $30 \%$ in the population. The other three ethnicity options, African American, Asian, and other did not match; all had percentages below 15\% for both population and sample.

Research Question One considered the independence of the nominal variables WALK and RET; the null hypothesis was: There is no relationship between retention and participation of students in the walking program. With a $p$-value of 0.003 , the null hypothesis was rejected. There is strong evidence to indicate that there is a relationship between student walkers and retention.

Regarding the second and third research questions, the ideal methodology would be to combine them and use logistic regression to evaluate the effects of both NMW and NPS on retention. However, not having a minimum of 100 participants required the use of a different statistical test. The Fisher's Exact Test was used for both Research Question Two and Research Question Three. In SPSS, a Fisher's Exact Test is run exactly as a Chi-Squared Test. However, if any of the expected values are less than five, a Chi-Squared test cannot be used, and the Fisher test is the default. Fisher's Exact Test is specific and appropriate for small sample sizes (Kim, 
2017). In both cases, the reason two of the expected values were less than five was because the sample size was small.

The first application of Fisher's Exact Test was to consider the relationship between number of minutes per day walking and retention. The American Heart Association (2018) recommends that adults spend a minimum of 150 minutes per week engaging in moderateintensity aerobic physical activity, which equates to 21.4 minutes per day. Using 21.4 minutes as a cut-off value, the variable number of minutes walked per week was dichotomized. The resulting $p$-value was 0.587 , indicating there was insufficient evidence to suggest there is a relationship between the number of minutes students walk per day and retention.

The number zero was used to dichotomize "number of people spoken to" (NPS), since the literature clearly indicated it is important for students to engage with peers or faculty (Bonet \& Walters, 2016, Lillis, 2011, Peck, 2011). Using zero people spoken to as a cut-off value, the variable NPS was dichotomized and a Fisher's Exact Test was used for the analysis. The $p$-value was 0.806 ; there was insufficient evidence to suggest that there is a relationship between NPS and retention.

\section{Findings Related to the Literature}

The current study was guided by two theoretical frameworks: Ajzen's Theory of Planned Behavior, (Ajzen, 2006) and Tinto's (1993) Model of Institutional Departure. Tying these theories together, the researcher sought to examine the behavior of a student as it relates to walking, engaging and retention. Ajzen's theory focused on attitude, subjective norms, and perceived behavioral control; how these predict intention; and how intention predicts behavior. Related to the current study, the first three constructs would be a student's questions: "What do I think about staying in college?" "What will others think about my staying?" "Can I do it?" If 
the answers to these questions allow a student to intend to be retained, then the resulting behavior would be to sign up for classes the following semester (Rhodes \& Nigg, 2011). For those in the walking program, all but two made the decision to be retained in college. In order to delve more deeply into the thoughts and how the decisions were made by the participants, a mixed methods study would be appropriate. Regarding the perceived behavior control of the students, knowing the grade point averages (GPAs) of the participants may give insight into how students would answer the question "Can I do it?" It is possible that students in the program, who are all volunteers, are self-motivated and therefore have higher GPAs than those in the matched sample.

Tinto (1993), in his Theory of Institutional Departure, named several constructs that lead to retention. Related to the current study are the informal faculty/staff and peer group interactions, and social integration. For the purposes of the present study, social integration was measured by the number of people spoken to while walking. Tinto's (1993) Theory of Institutional Departure would have predicted that the current study would find a relationship between number of people spoken to and retention. However, the current study, with regard to Research Question Three, found no such relationship.

The two main constructs for this study were moderate physical activity and student interaction with peers, college employees, or both. For the purpose of the current study, moderate physical activity was measured by "number of minutes walking" per day. interaction was measured by "number of people spoken" to while walking. These two constructs were considered as they related to student retention in a community college.

Several studies concerning moderate physical activity were discussed in Chapter Two. In particular, Slade and Kies (2015) studied the relationship between first-year medical students' 
use of campus recreational facilities (CRFs) and exam grades. Their analyses led to the conclusion that as moderate physical activity increased, so did grades. Inversely, as activity decreased, so did grades. Fike and Fike (2008), and Gershenfield, Hood, and Zhan (2016) also studied student grades. They considered grades as the independent variable and concluded that good grades lead to retention. Considering these three studies together, moderate physical activities lead to higher grades and good grades lead to retention. The findings from the first research question of the current study support the conclusions of Fike and Fike (2008), Gershenfield, et al. (2016), and Slade and Kies (2015) because the data indicated there is a relationship between moderate physical activity and retention.

Huesman, et al. (2009) also studied student use of CFRs; their population was four-year institutions. Their results led to the conclusion that there are positive relationships between CFR usage and both retention and graduation rates. Since one of their dependent variables was retention, this study more closely resembled and confirmed the results of Research Question One in the current study. Although the conclusions of the first research question in the current study agreed with those of Slade and Kies (2015) and Huesman, et al. (2009), the results of the second research question conflicted with the findings of these two studies. For that question, the null hypothesis was: There is no relationship between NMW and retention. That hypothesis was not rejected; that is, there was insufficient evidence to reject the null hypotheses.

Bonet and Walters (2016) studied learning communities, specifically at a community college. A learning community is a cohort of students who travel together between classes usually three: a developmental English course and two other general education courses. These authors came to the same conclusion as Tinto (1993): student interaction with other students and faculty mentors lead to retention. The current study used the Fisher's Exact Test to test the null 
hypothesis: There is no relationship between "number of people spoken to" (NPS) and retention. The data in the current study did not support rejecting the null hypothesis. Therefore, it cannot be concluded that there is a relationship between NPS and retention. The results were contrary to those of Tinto (1993) and Bonet and Walters (2016).

The failure to reach the minimum number of participants for use of the logistic regression analyses was an unanticipated problem, and as a result, may have led to surprising findings. In this small exploratory study, it was necessary to have at least 100 students volunteer to walk and record data in order to answer the original second research question with the desired methodology. The researcher did not anticipate how difficult the recruiting process would be. After a slow start during the first week, the researcher was permitted to speak directly to students in classrooms to increase participation. As a result, 119 students signed up, but many did not walk even once. Others were not included in the sample for other reasons including graduation in December 2019.

Unanticipated findings. There were two unanticipated findings in the current study; both were as a result of the small sample size which required the Fisher Exact Test to be used for the second and third research questions. Contrary to a plethora of conclusions in the literature concerning the positive relationship between moderate physical activity and ultimately retention, the results of the second research question in the present study showed no reason to draw that conclusion. Similarly, the second application of Fisher's Exact Test, used for Research Question Three in the current study, yielded an unanticipated finding: there was insufficient evidence to conclude that the number of people spoken to while walking was related to retention in the Spring 2020 semester. 
These unanticipated findings can be attributed to the sample size, which needed to be at least 100 in order to use logistic regression. Logistic regression would have considered both NMW and NPW together in relation to RET. Another reason for these findings was the very small number (two) of participants that did not enroll for the Spring 2020 semester. While this low number is good news for the students and college, it did not permit the researcher to use a Chi Square Test of Independence for the second and third research questions as an alternative to logistic regression.

\section{Discussion}

The results of Research Question One have promising implications. The null hypothesis for this question was: there is no relationship between walking and retention. The Chi-Squared analysis produced a very small $p$-value $(p=0.003)$, allowing the researcher to reject the null hypothesis. The result of this analysis indicated strong significance for the relationship between walking and retention.

Although the excellent retention rate of the participants in the current study cannot be completely attributed to the walking program, it can be logically concluded that walking and the subsequent interaction between students and college employees were contributing factors. These results are very promising for community college leaders interested in increasing retention at a very low cost. Of note, in the current study, one faculty member added one weekly office hour to his schedule; it was held outside while walking. For this Biology professor, these outdoor office hours provided his classes to have the opportunity of mini-field trips. Students were able to observe and ask questions related to the flora and fauna on and around the campus. Since this phenomenon was not measured in any way, the researcher does not know the extent of success of the Biology professor's extra office hour. 
Regarding Research Questions Two and Three, an abundance of literature led the researcher to believe that analyses in the present study would indicate strong positive relationships between (a) the number of minutes walking and retention and (b) the number of people spoken to and retention. Therefore, it was surprising that the statistical tests concluded no significant relationship. Ultimately, it was the size of the sample that hindered use of logistic regression. Ideally, the sample size needed to be at least 100 in order for the researcher to use the more desired logistic regression analysis. The next logical methodology was the Chi Square Test of Independence. Ironically, the fact that only two student walkers did not enroll made use of the Chi Square Test impossible because two of the cells had expected values that were less than five. As a result, Fisher's Exact Test was used for the second and third research questions. Since neither showed significance, conclusions about neither (a) the relationship between the number of minutes walking and retention nor (b) the relationship between the number of people spoken to and retention could be made. The only conclusion drawn for these research questions was if the study is replicated, the sample size needs to be significantly larger.

Related to the second research question, studies by Downs, et al. (2014), Slootmaker, et al. (2009), and Tucker et al. (2011) have shown that there is a significant discrepancy of reported data between those who self-report and those who wear accelerometers. In all studies, those who self-reported overestimated the number of minutes they actually engaged in moderate physical activity. These results need to be considered when making conclusions related to NMW. In the current study, NMW was not found to be significant in relation to retention, but perhaps if accelerometers were worn by participants for recording, the results may have been different.

There were many comments made to the researcher by some students and several faculty members. Most were positive; both students and especially faculty were grateful for the 
opportunity to get outside and exercise. Some faculty embraced the idea of having a smaller faculty-to-student ratio by participating in the program.

The written recognition on the large campus banners provided the opportunity for walkers - and the entire college community - to see their names in print each time they attained 10,25 , or 50 miles. In addition to writing names on prominent banners. the " 50 -Mile-Club" bumper stickers were also motivating. Nine of the 69 student participants walked between 50 and 53 miles, confirming their goal of finishing 50 miles. Additionally, several walkers who reached 50 miles were in the office of the researcher very quickly after attaining that goal to claim their bumper sticker.

Faculty expressed the challenge of speaking to students while walking. Many students walk with headphones on, making it difficult for other students or non-students to initiate the type of interaction Tinto (1993) encouraged. Students without headphones often had their heads down looking at their personal devices. Further, some faculty and staff do not have the personality to approach students they do not know.

\section{Limitations}

The following were limitations of the current study:

- Participants were recruited in a variety of ways, but ultimately, they needed to volunteer. In order for a student to have been a participant in the walking program, s/he must have taken the initiative to send an email to the researcher in order to receive a Google sheet and begin recording. No student was required to join.

- Data were self-reported by students.

- It is possible that students who joined the walking program were motivated individuals and therefore more likely to be retained regardless of participation in the program. 
- Many factors can affect retention. A student could have walked a great deal, and benefitted from the interaction, but a family situation, job change, or dozens of other factors could have negatively affected retention. These factors were out of the control of the researcher.

- There may have been unobserved characteristics of individuals who participated in the study that may have affected the outcome of retention (Huesman, et al., 2009). For example, a student may have taken classes at both campuses, limiting the amount of time $\mathrm{s} /$ he was available to walk.

- The lack of generalizability of the results of the current study across various postsecondary institutions was a limitation. Logistics required that the current research focus on one mid-sized public community college.

- The sample size was not large enough to use logistic regression, as planned. Therefore, the variables NMW and NPS were analyzed with RET individually.

- The instrument that was used to gather data was the previously described Google sheet; there was one for each participant. One threat to the internal consistency reliability (Leedy \& Ormrod, 2016) of this instrument was the proper use by each student using it. Some examples of improper uses are forgetting to make entries, accidentally making inaccurate entries, and purposely entering false values.

- One threat to the validity of the study was the response rate; the sample size was not large enough for the planned logistic regression analysis of the second and third questions.

- Response burden is a threat to the validity of the instrument because participants may have become fatigued in recording data. The Hawthorne effect is the phenomenon in which subjects in a study change their behavior because they know what the study is 
looking for and participation affords them special attention (Sprintall, 2012). For physical activity measure, it is also called reactivity. This effect was a threat to the internal validity of this study, especially because students who reached 25 and 50 miles were rewarded and had their names posted on campus for having reached these milestones.

- Instrument validity was threatened due to activity recall and report. According to studies by Slootmaker, Schuit, Chinapaw, Seidell, and VanMechelen (2009) and Tucker, Welk, and Beyler (2011), individuals who both self-report physical activity data and wear accelerometers significantly overestimate activity using self-reported methods. Downs, Van Hoomissen, Lafrenz, and Julka (2014) conducted a similar study with only college students and came to the same conclusion.

- In an effort to encourage students to participate in the study, some instructors offered modest academic incentives, such as a single point on an exam. Some students may have been inclined to falsify data related to their participation in an effort to receive a small incentive, threatening the internal validity of the current study.

- Attrition was a threat to the internal validity of this study; participants who signed up but did not participate decreased the sample size.

- Having a comparison group strengthened the internal validity of the current study.

- The fact that the current study took place at only one community college was a threat to the external validity of this study. Care should be taken when drawing conclusions for institutions other than Suburban. 


\section{Recommendations for Leaders}

The data from the current study indicated that participation in a walking program that provides the opportunity for socialization can improve student retention at a community college. Given that community colleges have fairly poor retention rates, a walking program is an option for improving these rates at little or no cost. The only expenses associated with the current study were fliers for recruitment and motivation-related materials: large banners and bumper stickers Retention of students at community colleges has a broad effect on many community college stakeholders. As was mentioned in Chapter One, college presidents, academic vice presidents, and retention specialists have a vested interest in improving student retention. Retaining students results in higher enrollment rates which correspond to full-time equivalent (FTE) metrics, and ultimately funding that relies on FTEs. Further, retention rates are tied to performance-based funding, another reason for these same stakeholders to be interested in improving retention rates.

With the current demographics and declining number of 18 to 20 -year-olds, retention efforts at community colleges are heightened. A walking program is an innovative approach to improving retention and ultimately to increasing student success. The researcher recommends that leaders employ a walking program, similar to the one in the current study, that encourages students to participate in some form of physical activity.

With the increase of Guided Pathways implementation at community colleges, many institutions are employing "meta-majors" or "communities," which are groups of programs that students choose to enter, depending on their interests and career goals. These groupings give students an identity and promote the sense of belonging which O'Keeffe (2013) and Tinto (1993) found to lead to student retention. Community college leaders can capitalize on the concept of meta-majors to infuse physical activity. For example, there could be friendly volleyball, 
badminton, kickball, or walking competitions. These suggested activities may be done indoors or outdoors, depending on the individual college facilities. College leaders could use low-cost motivational devices that were successful in the current study, such as banners and bumper stickers, to encourage their own students to participate.

Many community college students are working one or two jobs or have family responsibilities, signs of economic stress. As a result of these obligations, some students arrive at college, park their cars, rush to class, then return to their vehicles. These are commuter students who do not partake in any extra-curricular activities. A college-wide walking program as the one in the current study is a simple, convenient, and no-cost opportunity for these students to interact with other students, faculty, and staff with whom they may have no other opportunity to connect. It is a way for them to experience a sense of belonging to the college community, which is so important for student retention.

The current threat nationwide of decreasing enrollment means fewer students and, therefore, fewer classes as well as a decreased need for space. As a result, all college stakeholders must be concerned about the need to address the problem of student retention at community colleges. The jobs of faculty, student services personnel, food service employees, security guards and maintenance workers could be in danger if enrollment numbers are too low. Therefore, the results of the current study are of interest to all stakeholders at community colleges. Community college leaders can use the walking program as a way to engage all employees of the college in a retention strategy for students and may save jobs in the process.

Four-year institutions of higher education are much more likely than community colleges to have students spending more time on campus and therefore, interacting with faculty and staff. Undergraduates at four-year institutions are more likely to be full-time; these institutions have 
dormitories, large student services departments which offer a wide variety of clubs and organizations that allow students to integrate into campus life. Additionally, they have large recreation facilities with multiple areas of focus.

Community colleges have smaller student services staff; and fewer clubs, organizations, and organized social events. Given that community college students often work, have family obligations, and many attend college part-time, they do not have the same opportunities for social interaction or exercise as their four-year counterparts. Opportunities for interaction with faculty and staff are limited. Walking is an easy option a community college can provide to connect busy students who have multiple responsibilities with faculty and staff. Leaders should consider a walking program which is especially effective because it need not be restricted by day or time. By implementing such a program, community college leaders can provide opportunities for students to engage in moderate physical activity so important for retention (Boney \& Walters, 2016; Lillis, 2011). By making a commitment to a walking program, a community college is striving to increase retention.

In implementing a program for walking, leaders would be providing students with an opportunity for social interaction with peers and faculty that would not typically be found at a community college. Social integration is vital to first-year college students' retention. It can be especially helpful to students who may feel marginalized because of race, ethnicity, language, sexual orientation or learning ability (e.g., autism) to acclimate better to college life. Students from these same populations often have low success rates. A walking program can give all students the sense of belonging so crucial to student retention (Bippus, Kearney, Plax, \& Brooks, 2003; Skari, 2014; Tinto, 2017). 
Research on student retention indicated each student experiences higher education differently (Tinto, 1993). Community colleges have a particular interest in improving the student experience, because retention means student success and boosting their bottom line. Beyond retention, it is important for a student's success that the transition from high school to college be as smooth as possible. Programs like the walking program fit well, as students are integrated into the college community early. For many community college students, improving the quality of the college experience is not found in academics; rather it is in social acclimation. Tinto (1993) indicated that students often drop out of college because they do not feel socially integrated or cannot connect with others as rapidly as other students. His Theory of Institutional Departure stated that social interaction is a critical element for students as they consider retention.

Community college leaders of today are struggling with retention, persistence, and graduation rates. The walking program discussed in the present study offers a blueprint for a relatively simple and very cost-effective strategy for improving student retention. Moderate physical activity combined with interaction leads to personal connections, retention, and student success.

The researcher was unexpectedly very dependent on others to get students to enroll in the program. After a sluggish first week of students joining, there needed to be another tactic. Speaking in classrooms was extremely helpful; without that help there would have been an even smaller sample size. Having the support of the larger college community, in particular the toplevel administrators, would have been very helpful in promoting participation. This support would likely have brought the number of student walkers above 100, which would have allowed for the use of logistic regression to address NMW and NPS as they related to retention. Therefore, the researcher suggests that leaders show full support of the walking program. This 
support could be in the form of emails to the student and college-wide community. As a stronger tactic, the college president and vice presidents could be active participants. If students saw upper administrators outside walking and offering the opportunity for conversations, they would likely be eager to participate and feel the critical sense of belonging so important in Tinto's (1993) Model of Institutional Departure, a guiding theoretical framework for the current study.

\section{Recommendations for Future Research}

One of the limitations of the current study was the way students became participants. Regardless of the many efforts put forth for recruiting student walkers, students ultimately needed to volunteer. As a result, the sample size was relatively small. Sixty-nine student participants were eligible to be included in the analyses. For future studies, this researcher recommends another approach to enlisting participants. For example, if a relationship with an accelerometer manufacturing company were to be established, the company may be willing to give these fitness devices to the college in exchange for advertising. Then students may be more inclined to participate in a walking program. Another recommendation would be to make a walking class mandatory. The instructor could pair or group students for walks, rotating the composition of each group weekly.

In the current study, students self-reported data. This method relied on the accuracy of students keeping track of number of minutes walked and number of people spoken to while walking. If a student is engaged in conversation, s/he may be distracted and enter erroneous data or not enter data at all. Additionally, earlier studies concluded that self-reporting data for moderate physical activity is much less accurate than data gleaned from an accelerometer. A recommendation to alleviate the limitation of self-reporting the number of minutes walked is to have each student wear an accelerometer. Without the distraction of recording time spent 
walking, the participant would be able to focus solely on the number of people spoken to. This way, more attention would be given to the social interactions of the participants.

As an exploratory study, the present research was conducted at only one community college. Future researchers may consider a multi-institutional study. A larger sample size would allow the second and third research questions to be written as one and analyzed using logistic regression.

Wirt and Jaeger (2014) noted that faculty spend close to $90 \%$ of their time on campus teaching. They already spend many hours in contact with students. Future researchers may want to consider a study with student interactions specifically focused on non-faculty personnel.

The researcher received many unsolicited, informal reactions to the walking program. These comments were from students and non-students; some were suggestions, others were compliments. Future researchers may consider conducting a mixed-method study. With that approach, the qualitative constructs of reactions, concerns, and feelings of participants may be captured and looked at along with quantitative data.

Finally, it was observed that there was an increase in student participants after encouragement to students in a classroom by the researcher and faculty member. Therefore, for future research, it is recommended that the researcher bring as many college personnel on board as possible. Having a college president commit to and promote the research would be especially helpful.

\section{Concluding Remarks}

There is solid evidence in the literature to conclude that moderate physical activity is beneficial to overall health (USDHHS, 2018), better grades (Slade \& Kies, 2015), motivation (Aung, Somboonwong, Jaroonvanichkul, \& Wannakrairot, 2016), and retention (Huesman, 
Brown, Lee, Kellogg, \& Radcliffe, 2009). The literature is also abundant with conclusions of the positive results of social integration as it leads to sense of belonging (Bippus, Kearney, Plax, \& Brooks, 2003; Skari, 2014; Tinto, 2017);), better grades (Grantham, Robinson, \& Chapman, 2015), motivation (Trolian, Jach, Hanson, \& Pascarella, 2016), and retention (Peck, 2011; Wirt \& Jaeger, 2014).

The results of Research Question One gave strong indication that student participation in moderate physical activity and interaction with others results in retention. The results for the second and third research questions were unexpected; however, they do give important information concerning the implication of the findings. The results of Research Question Two were there was no significance between the NMW and retention. However, that conclusion alone is an important finding. Since less than half of college students and less than half of all Americans meet the minimum guidelines of the AHA (Melton et al., 2016), this study indicates that walking shorter distances still has a positive effect on retention. Similarly, Research Question Three gives important information. Although no significance was found between NPS and retention, even walking alone can be beneficial in retaining students.

The current study was focused on community college students who have very few opportunities for social interaction. There are few clubs, organizations, and social events that exist, and those that do meet at very specific times not conducive to the schedules of many community college students who have commitments outside of college. A walking program that promotes moderate physical activity and social interaction at any time on any day is a way for community college students to connect with other students, faculty members, and staff and become more connected to the campus. Implementing such a walking program is easy and leaders should recognize the potential for the opportunity to engage students. A walking 
program similar to the one in the current study can be replicated at larger scales as a low-cost retention improvement strategy for community college students. 


\section{References}

Ajzen, I. (2006). Theory of Planned Behavior Diagram. Retrieved from https://people.umass.edu/aizen/tpb.diag.html

American Association of Community Colleges (2019). Voluntary Framework of Accountability Metrics Manual Version 8. Washington, DC: American Association of Community Colleges. Retrieved from https://vfa.aacc.nche.edu/Documents/VFAMetricsManual.pdf

American Association of Community Colleges (2020). Fast Facts. Retrieved from https://www.aacc.nche.edu/research-trends/fast-facts

American Heart Association. (2018). American Heart Association recommendations for physical activity in adults and kids. Retrieved from https://www.heart.org/en/healthyliving/fitness/fitness-basics/aha-recs-for-physical-activity-in-adults

Aung, M. N., Somboonwong, J., Jaroonvanichkul, V., \& Wannakrairot, P. (2016). Possible link between medical students' motivation for academic work and time engaged in physical exercise. Mind, Brain \& Education, 10(4), 264-271. doi:10.1111/mbe.12121

Bahr, P. R., \& Gross, J. L. (2016). Community colleges. In M. N. Bastedo, P. G. Altbach, \& P. J. Gumport, (Eds.). American higher education in the twenty-first century (pp. 462-502). Baltimore, MD: Johns Hopkins University Press.

Ball, K., Abbott, G., Wilson, M., Chisholm, M., \& Sahlqvist, S. (2017). How to get a nation walking: Reach, retention, participant characteristics and program implications of Heart Foundation Walking, a nationwide Australian community-based walking program. International Journal of Behavioral Nutrition \& Physical Activity, 14(1). doi:10.1186/s12966-017-0617-5 
Beal, P. E., \& Noel, L. (1980). What works in student retention: The report of a joint project of the American College Testing Program and the National Center for Higher Education Management Systems. Available from: American College Testing Program, Iowa City, IA. ED 197635

Benson, T. A., Cohen, A. L., \& Buskist, W. (2005). Rapport: Its relation to student attitudes and behaviors toward teachers and classes. Teaching of Psychology, 32(4), 237-270.

Bippus, A. M., Brooks, C. G., Plax, T. G., \& Kearney, P. (2001). Students’ perceptions of parttime and tenured/tenure-track faculty: Accessibility, mentoring, and extra-class communication. Journal of the Association for Communication Administration, 30, 1323.

Bippus, A. M., Kearney, P., Plax, T. G., \& Brooks, C. F. (2003). Teacher access and mentoring abilities: Predicting the outcome value of extra class communication. Journal of Applied Communication Research, 31(3), 260-275.

Bjornsen, C. A., Archer, K. J., Gurung, R. A. R., \& Landrum, R. E. (2015). Relations between college students' cell phone use during class and grades. Scholarship of Teaching and Learning in Psychology, 1(4), 326-336.

Boggs, G. (2011). The American community college: From access to success. About Campus, $16(2), 2-10$.

Bonet, G., \& Walters, B. R. (2016). High impact practices: Student engagement and retention. College Student Journal, 50(2), 224-235.

Bopp, M., Bopp, C. M., Duffey, M. L., Ganim, R., \& Proctor, D. N. (2015). Implementation and evaluation of an Exercise is Medicine ${ }^{\mathrm{TM}}$ on Campus week. Evaluation and Program Planning, 52, 176-181. 
Boyle, J., Mattern, C. O., Lassiter, J. W., \& Ritzler, J. A. (2011). Peer 2 peer: Efficacy of a course-based peer education intervention to increase physical activity among college students. Journal of American College Health, 59(6), 519-529.

Calcagno, J. C., Bailey, T., Jenkins, D., Kienzl, G., \& Leinbach, T. (2008). Community college student success: What institutional characteristics make a difference? Economics of Education Review, 27, 632-645.

Centers for Disease Control and Prevention. (2019). Benefits of physical activity. Retrieved from https://www.cdc.gov/physicalactivity/basics/pa-health/index.htm

Cohen, E. (2018). Gendered styles of student-faculty interaction among college students. Social Science Research, 75, 117-129.

Cox, B. E. (2011). A developmental typology of faculty-student interaction outside the classroom. New Directions for Institutional Research, 2011, 49-66. doi:10.1002/ir.416

Dewey, J. (1927). The public and its problems. In Boydston, J. A., (Ed.). John Dewey: The later works 1925-1953 (p. 235-372). Carbondale, IL: Southern Illinois University Press.

Diez, D. M., Barr, C. D., \& Cetinkaya-Rundel, M. (2014). Openintro statistics ( ${ }^{\text {rd }}$ ed.). Retrieved from https://drive.google.com/file/d/0B-DHaDEbiOGkc1RycUtIcUtIelE/view

Downs, A., VanHoomissen, J., Lafrenz, A., \& Julka, D. L. (2014). Accelerometer-measured versus self-reported physical activity in college students: Implications for research and practice. Journal of American College Health, 62(3). Retrieved from https://www.tandfonline.com/doi/full/10.1080/07448481.2013.877018

Exercise is Medicine. (2018). Retrieved from https://www.exerciseismedicine.org/support page.php/exercise-professionals/ 
Fike, D. S., \& Fike R. (2008). Predictors of first-year students in the community college. Community College Review, 36(2), 68-88.

Flanigan, A., \& Kiewra, E. (2018). What college instructors can do about student cyber-slacking. Educational Psychology Review, 30(2), 585-597.

Geiger, R. L. (2016). The ten generations of American higher education. In M. N. Bastedo, P. G. Altbach, \& P. J. Gumport, (Eds.). American higher education in the twenty-first century (pp. 3-34). Baltimore, MD: Johns Hopkins University Press.

Gershenfeld, S., Hood, D. W., \& Zhan, M. (2016). The role of first-semester GPA in predicting graduation rates of underrepresented students. Journal of College Student Retention: Research, Theory \& Practice, 17(4), 469-488.

Grantham, A., Robinson, E. E., \& Chapman, D. (2015). "That truly meant a lot to me": A qualitative examination of meaningful faculty-student Interactions. College Teaching, $63(3), 125-132$.

Hillman, C. H., Erickson, K. I., \& Kramer, A. F. (2008). Be smart, exercise your heart: Exercise effects on brain and cognition. Nature Reviews Neuroscience, 9(1), 58-65.

Hoeger, W. W., Bond, L. M., Ransdell, L., Shimon, J., \& Merugu, S. (2008). One-mile step count at walking and running speeds. ACSM's Health \& Fitness Journal, 12(1), 14-19.

Huesman, R., Brown, A., Lee, G., Kellogg, J., \& Radcliffe, P. (2009). Gym bags and mortarboards: Is use of campus recreation facilities related to student success? Journal of Student Affairs Research and Practice, 46(1), 50-71. 
Joubert, L., Kilgas, M., Riley, A., Gautam, Y., Donath, L., \& Drum, S. (2017). In-class cycling to augment college student academic performance and reduce physical inactivity: Results from an RCT. International Journal of Environmental Research and Public

Health, 14(11), doi:10.3390/ijerph14111343

Juszkiewicz, J. (2019). Trends in community college enrollment and completion data, Issue 5 (American Association of Community Colleges). Retrieved from https://www.aacc.nche.edu/?s=Trends + in + community + college + enrollment + and + complet $\underline{\text { ion }+ \text { data } \% 2 \mathrm{C}+\text { Issue }+5+}$

Karp, M., Hughes, K., \& O'Gara, L. (2010). An exploration of Tinto's Integration Framework for community college students. Journal of College Student Retention, 12(1), 69-86.

Kassavou, A., Turner, A., \& French D. P. (2013). Do interventions to promote walking in groups increase physical activity? A meta-analysis. International Journal of Behavioral Nutrition and Physical Activity, 10(1), 1-12. doi:10.1186/1479-5868-10-18

Kim H. Y. (2017). Statistical notes for clinical researchers: Chi-Squared test and Fisher's exact test. Restorative dentistry \& endodontics, 42(2), 152-155. doi:10.5395/rde.2017.42.2.152

Kimbark, K., Peters, M. L., \& Richardson, T. (2017). Effectiveness of the student success course on persistence, retention, academic achievement, and student engagement. Community College Journal of Research and Practice, 41(2), 124-138.

Komarraju, M., Musulkin, S., \& Bhattacharya, G. (2010). Role of student-faculty Interactions in developing college students' academic self-concept, motivation, and achievement. Journal of College Student Development, 51(3), 332-342.

Kuh, G. (2016). Making learning meaningful: Engaging students in ways that matter to them. New Directions for Teaching and Learning, 2016(145), 49-56. 
Leedy, P. D., \& Ormrod, J. E. (2016). Practical research: Planning and design (11th ed.). London, England: Pearson Education Limited.

Lepp, A., Barkley, J. E., Sanders, G. J., Rebold, M., \& Gates, P. (2013). The relationship between cell phone use, physical and sedentary activity, and cardiorespiratory fitness in a sample of U.S. college students. International Journal of Behavioral Nutrition \& Physical Activity, 10(1), 79.

Lillis, M. (2011). Faculty emotional intelligence and student-faculty interactions: Implications for student retention. Journal of College Student Retention, 13(2), 155-178.

Lobelo, F., Stoutenberg, M., \& Hutber, A. (2014). The Exercise is Medicine global health initiative: A 2014 update. British Journal of Sports Medicine, 48(22), 1627-1633.

Lundberg, C. A., \& Schreiner, L. A. (2004). Quality and frequency of faculty-student interaction as predictors of learning: An analysis by student race/ethnicity. Journal of College Student Development, 45(5), 549-565.

Martin, K., Galentino, R., \& Townsend, L. (2014). Community college student success: The role of motivation and self-empowerment. Community College Review, 42(3), 221-241.

McClenney K. M., \& Arnsparger, A. (2012). Students speak: Are we listening? Austin, TX: Center for Community College Student Engagement.

McKinney, L., \& Hagedorn, L. S. (2017). Performance-based funding for community colleges: Are colleges disadvantaged by serving the most disadvantaged students? The Journal of Higher Education, 88(2), 159-182.

McPhail, C. J. (2011). The Completion Agenda: A call to action. Summary report from the November 10-11 meeting of the American Association of Community Colleges and Board of Directors. Retrieved from https://files.eric.ed.gov/fulltext/ED532208.pdf. 
Melnyk, B., Kelly, S., Jacobson, D., Arcoleo, K., \& Shaibi, G. (2014). Improving physical activity, mental health outcomes, and academic retention in college students with Freshman 5 to Thrive: COPE/Healthy lifestyles. Journal of the American Association of Nurse Practitioners, 26(6), 314-322.

Melton, B., Williamson, J. A., Bland, H., \& Zhang, J. (2016). Using the Exercise is Medicine on campus platform to assess college students' practice of physical activity in a rural setting. Journal of the Georgia Public Health Association, 5(4), 360-364.

Nagamatsu, L., Flicker, L., Kramer, A., Voss, M., Erickson, K., Hsu, C., \& Liu-Ambrose, T. (2014). Exercise is medicine, for the body and the brain. British Journal of Sports Medicine, 48(12), 943-944.

National Center for Education Statistics. (2018). Digest of Education Statistics. Retrieved from https://nces.ed.gov/programs/digest/d19/tables/dt19 331.90.asp

National Center for Education Statistics. (2019a). Digest of Education Statistics. Retrieved from https://nces.ed.gov/programs/digest/d19/tables/dt19 326.30.asp

National Center for Education Statistics. (2019b). Digest of Education Statistics. Retrieved from https://nces.ed.gov/programs/digest/d19/tables/dt19 326.20.asp

National Center for Education Statistics (2019c). College Navigator. Retrieved from https://nces.ed.gov/collegenavigator/?id=194240\#retgrad

National Center for Education Statistics. (2019d). Digest of Education Statistics. Retrieved from https://nces.ed.gov/programs/digest/d19/tables/dt19 306.20.asp

National Physical Activity Plan Alliance. (2016). U.S. National Physical Activity Plan. Retrieved from: http://physicalactivityplan.org/docs/2016NPAP_Finalforwebsite.pdf 
National Physical Activity Plan Alliance. (2018). Promoting walking and walkable communities:

Cross-sector recommendations from the National Physical Activity Plan Alliance.

Columbia, SC.

National Student Clearinghouse. (2019). Persistence and retention. National, Persistence, Postsecondary, Snapshot Report. Retrieved from https://nscresearchcenter.org/snapshotreport35-first-year-persistence-and-retention/

Office of Disease Prevention and Health Promotion. (22, January 2020) Get active. Retrieved from https://healthfinder.gov/HealthTopics/Category/health-conditions-anddiseases/diabetes/get-active\#the-basics_1

O'Keeffe, P. (2013). A sense of belonging: Improving student retention. College Student Journal, $47(4), 605-613$

O'Riordan, F., \& Broughton, F. (2017). Care to Share? A study of the extent to which an expectation sharing and setting induction exercise is an effective pedagogical tool for first year law students. The All Ireland Journal of Teaching \& Learning in Higher Education, $9(1), 1-15$.

Pascarella, E. T., \& Terenzini, P. T. (1979). Student-faculty informal contact and college Persistence: A further investigation. The Journal of Educational Research, 72(4), 214 218. Retrieved from https://doi.org/10.1080/00220671.1979.10885157.

Pascarella, E. T., \& Terenzini, P. T. (2005). How college affects students: A third decade of research. San Francisco, CA: Jossey-Bass.

Pascarella, E. T., Wolniak, G. C., Pierson, C. T., \& Terenzini, P. T. (2003). Experiences and outcomes of first-generation students in community colleges. Journal of College Student Development, 44(3), 420-29. 
Pattison, P., Hale, J. R., \& Gowens, P. (2011). Mind and soul: Connecting with students. Journal of Legal Studies Education, 28(1), 39-66.

Peck, A. (2011). In practice: Peer involvement advisors improve first-year student engagement and retention. About Campus, 16(3), 22-25.

Phillips, B. (2019, June 5). I don’t care what you know until I know you care: Why caring campuses retain more students. The Evolllution. Retrieved from https://evolllution.com/attracting-students/retention/i-dont-care-what-you-know-until-i$\underline{\text { know-you-care-why-caring-campuses-retain-more-students/ }}$

Rhodes, R. E., \& Nigg, C. R. (2011). Advancing physical activity theory: A review and future directions. Exercise and Sport Sciences Reviews, 39(3), 113-119.

Romano, R. M., \& Palmer, J. C. (2016). Financing community colleges. Lanham, MD: Rowman \& Littlefield.

Sallis, R. (2009). Exercise is medicine and physicians need to prescribe it! British Journal of Sports Medicine, 43(1), 3-4.

Sathyanarayana-Rao, T. S. \& Tandon, A. (2016). Cognition. Journal of Geriatric Mental Health, 3(1), 1-2.

Schudde, L. T., \& Goldrick-Rab, S. (2016). Extending opportunity, perpetuating privilege: Institutional stratification amid educational expansion. In M. N. Bastedo, P. G. Altbach, \& P. J. Gumport, (Eds.). American higher education in the twenty-first century (pp. 345374). Baltimore, MD: Johns Hopkins University Press.

Shannon, H., Smith, R., Townsend, B. K., \& Dougherty, K. J. (2006). A case for the community college's open access mission. New Directions for Community Colleges, 2006(136), 1521. 
Sherman, B. (2017, March 20). Fitbit fitness monitoring program a hit at ORU. Tulsa World. Retrieved from https://www.tulsaworld.com/homepagelatest/fitbit-fitness-monitoringprogram-a-hit-at-oru/article_eae41a5e-830a-5270-98de-c1aa62aac28d.html

Skari, L. (2014). Community college alumni: Predicting who gives. Community College Review, 42(1), 23-40.

Slootmaker, S. M., Schuit, A. J., Chinapaw, M. J. Seidell, J. C., \& VanMechelen, W. (2009). Disagreement in physical activity assessed by accelerometer and self-report in subgroups of age, gender, education and weight status. International Journal of Behavioral Nutrition and Physical Activity, 6(17). Retrieved from https://ijbnpa.biomedcentral.com/articles/10.1186/1479-5868-6-17

Slade, A. N., \& Kies, S, M. (2015). The relationship between academic performance and recreation use among first-year medical students. Medical Education Online, 20(1), 1-8.

Smith, A., \& Anderson, M. (2018, March 1). Social media use in 2018. (Pew Research Center Report). Retrieved from http://www.pewinternet.org/2018/03/01/social-media-use-in$\underline{2018 /}$

Sprinthall, R.C. (2012). Basic statistical analysis (9 $9^{\text {th }}$ ed.). Boston, MA: Allyn \& Bacon.

The White House. (2009). Remarks of President Barak Obama-Address to Joint Session of Congress. (2009, February 24). Retrieved from https://obamawhitehouse.archives.gov/the-press-office/remarks-president-barack-obama$\underline{\text { address-joint-session-congress }}$

Tinto, V. (1993). Leaving college: Rethinking the causes and cures of student attrition. Chicago, IL: The University of Chicago Press.

Tinto, V. (2017). Reflections on student persistence. Student Success, 8(2), 1-8. 
Triola, M. (2019). Essentials of statistics (6th ed.). New York, NY: Pearson.

Trolian, T. L, Jach, E. A., Hanson, J. M., \& Pascarella, E. T. (2016). Influencing academic motivation: The effects of student-faculty interaction. Journal of College Student Development, 57(7), 810-826.

Tucker, J. M., Welk, G. J., \& Beyler, N. K. (2011). Physical activity in U.S. adults. Compliance with the Physical Activity Guidelines for Americans. American Journal of Preventive Medicine, 40(4), 454-461. doi:10.1016/j.amepre.2010.12.016

United States Department of Health and Human Services. (2018). 2018 Physical activity guidelines for Americans. Washington, DC.

VanKim, N. A., \& Nelson, T. F. (2013). Vigorous physical activity, mental health, perceived stress, and socializing among college students. American Journal of Health Promotion, $28(1), 7-15$.

Wirt, L. G., \& Jaeger, A. J. (2014). Seeking to understand faculty-student interaction at community colleges. Community College Journal of Research and Practice, 38(11), 980994.

Withall, J., Jago, R., \& Fox, K. (2011). Why some do but most don't. Barriers and enablers to engaging low-income groups in physical activity programmes: A mixed methods study. BMC Public Health, 11(1), 507.

World Health Organization (WHO). (2018, February 23). What is physical activity? Retrieved from https://www.who.int/news-room/fact-sheets/detail/physical-activity 
Young, D. R., Spengler, J. O., Frost, N., Evenson, K. R., Vincent, J. M., \& Whitsel, L. (2014). Promoting physical activity through the shared use of school recreational spaces: A policy statement from the American Heart Association. American Journal of Public Health, 104(9), 1583-1588.

Young, S. J., Sturts, J. R., \& Ross, C. M. (2015). Physical activity among community college students. Physical Educator, 72(4), 640-659.

Zhu, X., Haegele, J. A., \& Healy, S. (2019). Movement and mental health: Behavioral correlates of anxiety and depression among children of 6-17 years old in the U.S. Mental Health and Physical Activity, 16, 60-65. 


\section{Appendix A}

\section{Sample Student Google Sheet}

sample student tha

File Edit View Insert Format Data Tools Add-ons Help All changes saved in Drive

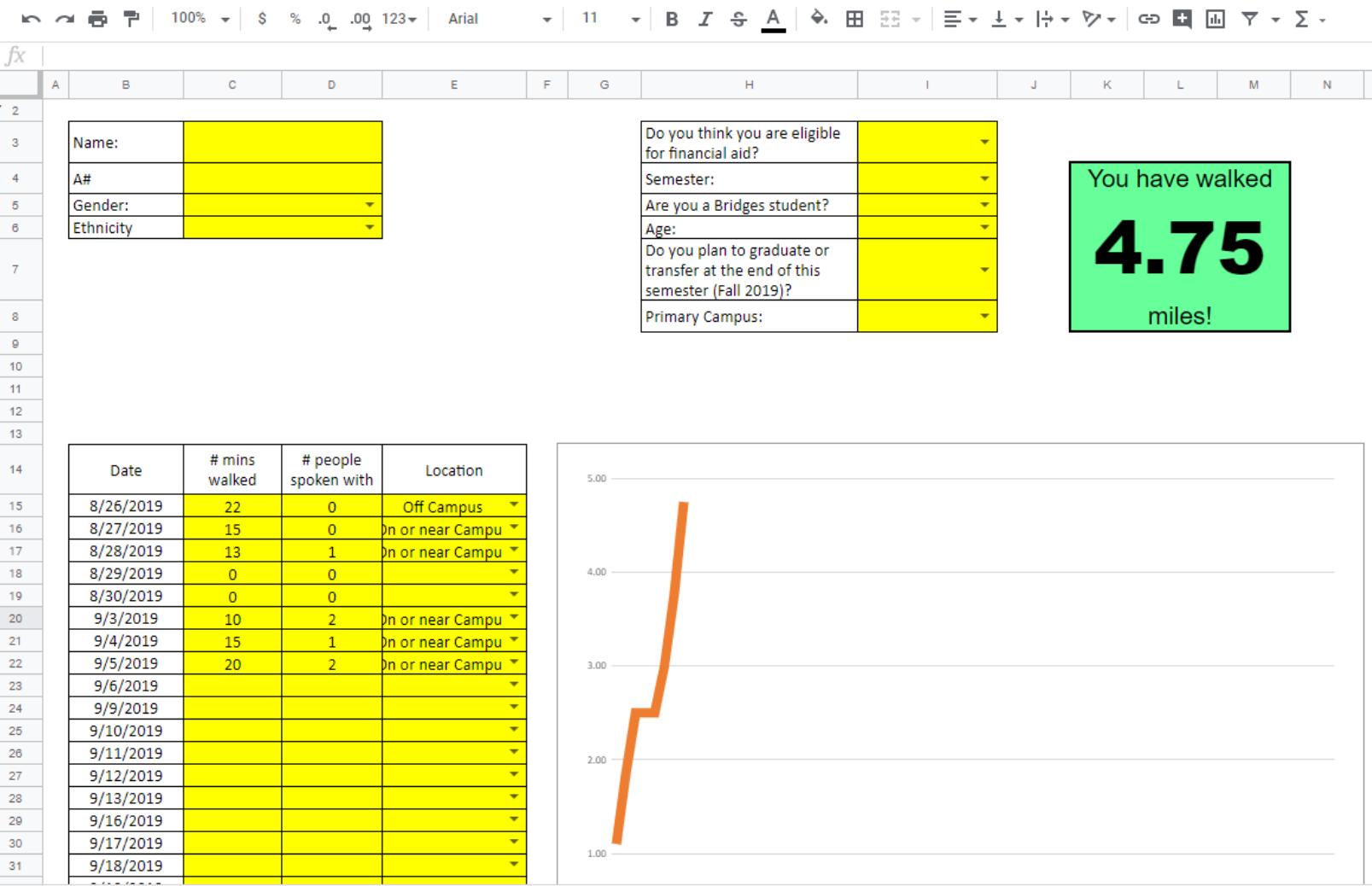




\section{Appendix B}

\section{Sample Non-Student Google Sheet}

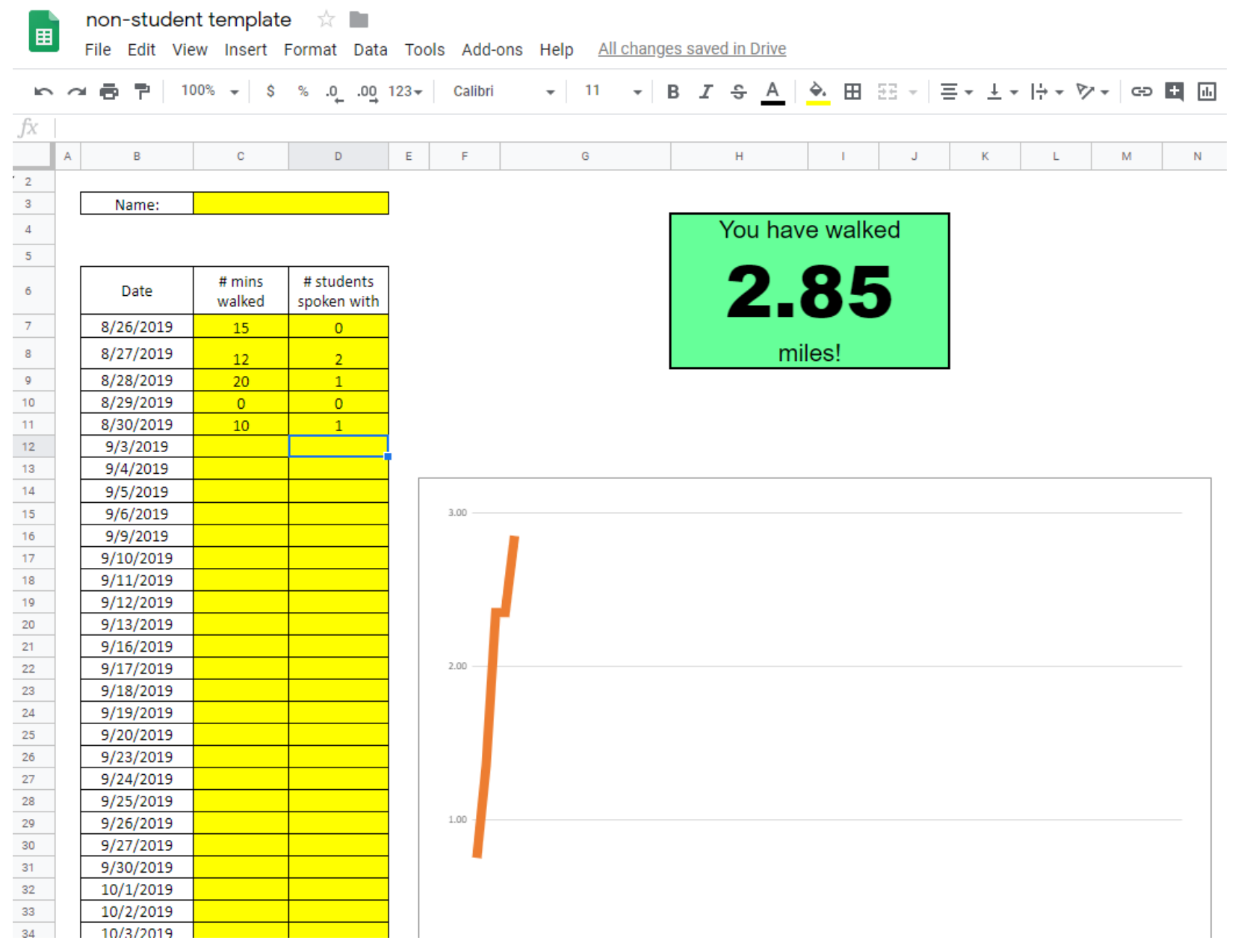




\section{Appendix C}

Summary of Data of Student Walkers

\begin{tabular}{|c|c|c|c|c|c|}
\hline $\begin{array}{l}\text { Student } \\
\text { Participant } \\
\text { number }\end{array}$ & $\begin{array}{l}\text { Student ID } \\
\text { \# (ID) }\end{array}$ & $\begin{array}{l}\text { Total \# } \\
\text { min. } \\
\text { walked } \\
\text { (Total } \\
\text { NMW) }\end{array}$ & $\begin{array}{l}\text { \# of days } \\
\text { walked } \\
(\mathrm{NDW})\end{array}$ & $\begin{array}{l}\text { Total \# of } \\
\text { people spoken } \\
\text { to (Total NPS) }\end{array}$ & $\begin{array}{l}\text { Enroll for } \\
\text { Spring } \\
2020 ? \text { Yes }= \\
1 \\
\text { No }=0\end{array}$ \\
\hline & & & & & \\
\hline & & & & & \\
\hline & & & & & \\
\hline & & & & & \\
\hline & & & & & \\
\hline & & & & & \\
\hline & & & & & \\
\hline & & & & & \\
\hline & & & & & \\
\hline & & & & & \\
\hline & & & & & \\
\hline & & & & & \\
\hline & & & & & \\
\hline & & & & & \\
\hline
\end{tabular}

Summary of Data from Matched Sample

\begin{tabular}{|l|l|l|}
\hline $\begin{array}{l}\text { \# of students } \\
\text { in matched } \\
\text { sample }\end{array}$ & $\begin{array}{l}\text { number } \\
\text { enrolled } \\
\text { Spring '20 }\end{array}$ & $\begin{array}{l}\text { number not } \\
\text { enrolled } \\
\text { Spring '20 }\end{array}$ \\
\hline & & \\
\hline
\end{tabular}




\section{Appendix D}

Flier for Recruitment

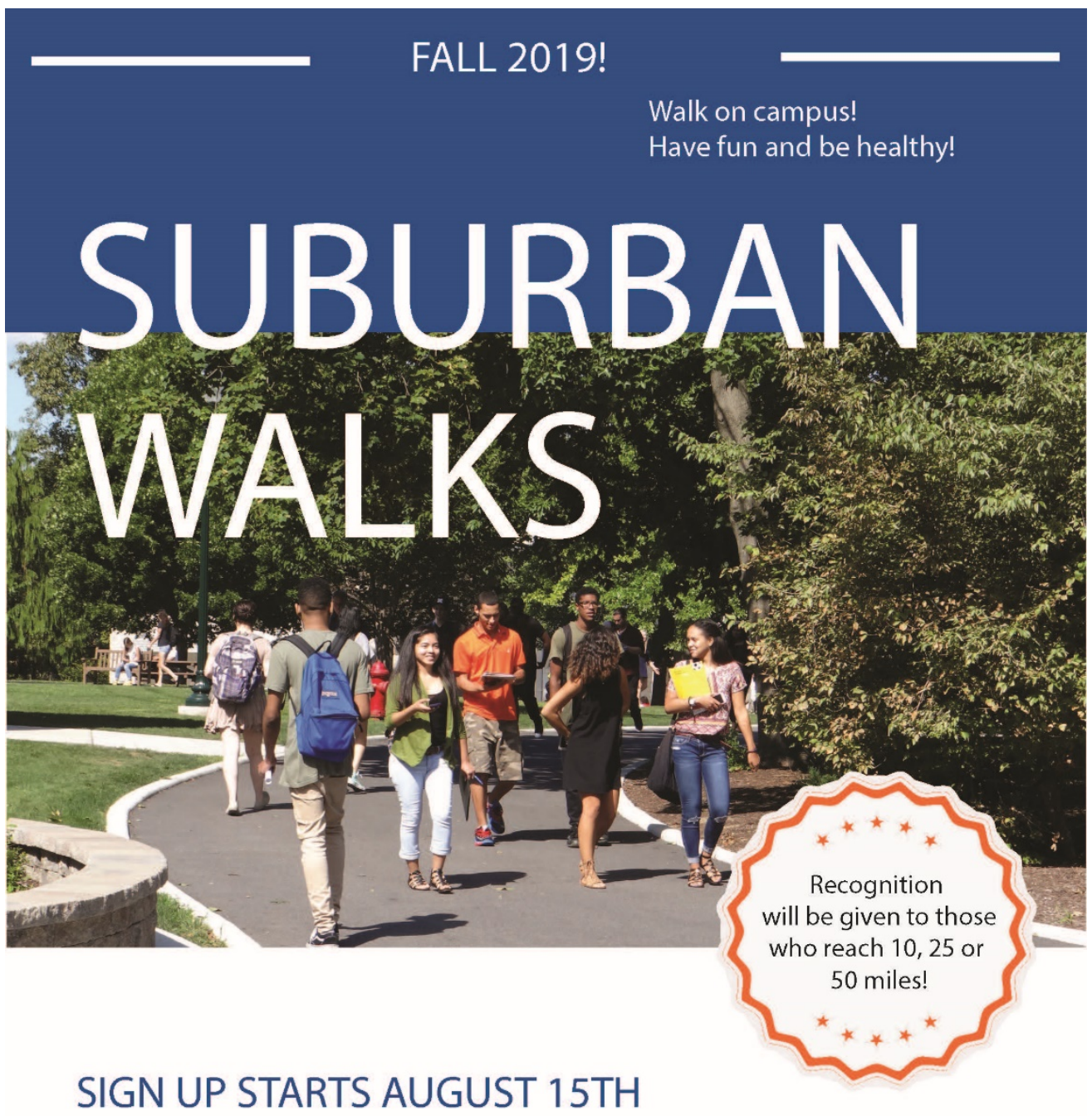

Email walk@suburban.edu 


\section{Appendix E}

Template for Banners

\section{Suburban Community College Walks!}

\begin{tabular}{|l|l|l|l|l|l|l|l|}
\hline \multicolumn{3}{|c|}{10} & \multicolumn{3}{c|}{ 25 Mile Club Club } & \multicolumn{2}{c|}{50 Mile Club } \\
\hline Name 1 & Name 19 & Name 37 & Name 55 & Name 73 & Name 91 & Name 109 & Name 127 \\
\hline Name 2 & Name 20 & Name 38 & Name 56 & Name 74 & Name 92 & Name 110 & Name 128 \\
\hline Name 3 & Name 21 & Name 39 & Name 57 & Name 75 & Name 93 & Name 111 & Name 129 \\
\hline Name 4 & Name 22 & Name 40 & Name 58 & Name 76 & Name 94 & Name 112 & Name 130 \\
\hline Name 5 & Name 23 & Name 41 & Name 59 & Name 77 & Name 95 & Name 113 & Name 131 \\
\hline Name 6 & Name 24 & Name 42 & Name 60 & Name 78 & Name 96 & Name 114 & Name 132 \\
\hline Name 7 & Name 25 & Name 43 & Name 61 & Name 79 & Name 97 & Name 115 & Name 133 \\
\hline Name 8 & Name 26 & Name 44 & Name 62 & Name 80 & Name 98 & Name 116 & Name 134 \\
\hline Name 9 & Name 27 & Name 45 & Name 63 & Name 81 & Name 99 & Name 117 & Name 135 \\
\hline Name 10 & Name 28 & Name 46 & Name 64 & Name 82 & Name 100 & Name 118 & Name 136 \\
\hline Name 11 & Name 29 & Name 47 & Name 65 & Name 83 & Name 101 & Name 119 & Name 137 \\
\hline Name 12 & Name 30 & Name 48 & Name 66 & Name 84 & Name 102 & Name 120 & Name 138 \\
\hline Name 13 & Name 31 & Name 49 & Name 67 & Name 85 & Name 103 & Name 121 & Name 139 \\
\hline Name 14 & Name 32 & Name 50 & Name 68 & Name 86 & Name 104 & Name 122 & Name 140 \\
\hline Name 15 & Name 33 & Name 51 & Name 69 & Name 87 & Name 105 & Name 123 & Name 141 \\
\hline Name 16 & Name 34 & Name 52 & Name 70 & Name 88 & Name 106 & Name 124 & Name 142 \\
\hline Name 17 & Name 35 & Name 53 & Name 71 & Name 89 & Name 107 & Name 125 & Name 143 \\
\hline Name 18 & Name 36 & Name 54 & Name 72 & Name 90 & Name 108 & Name 126 & Name 144 \\
\hline
\end{tabular}


Appendix F

Bumper Sticker

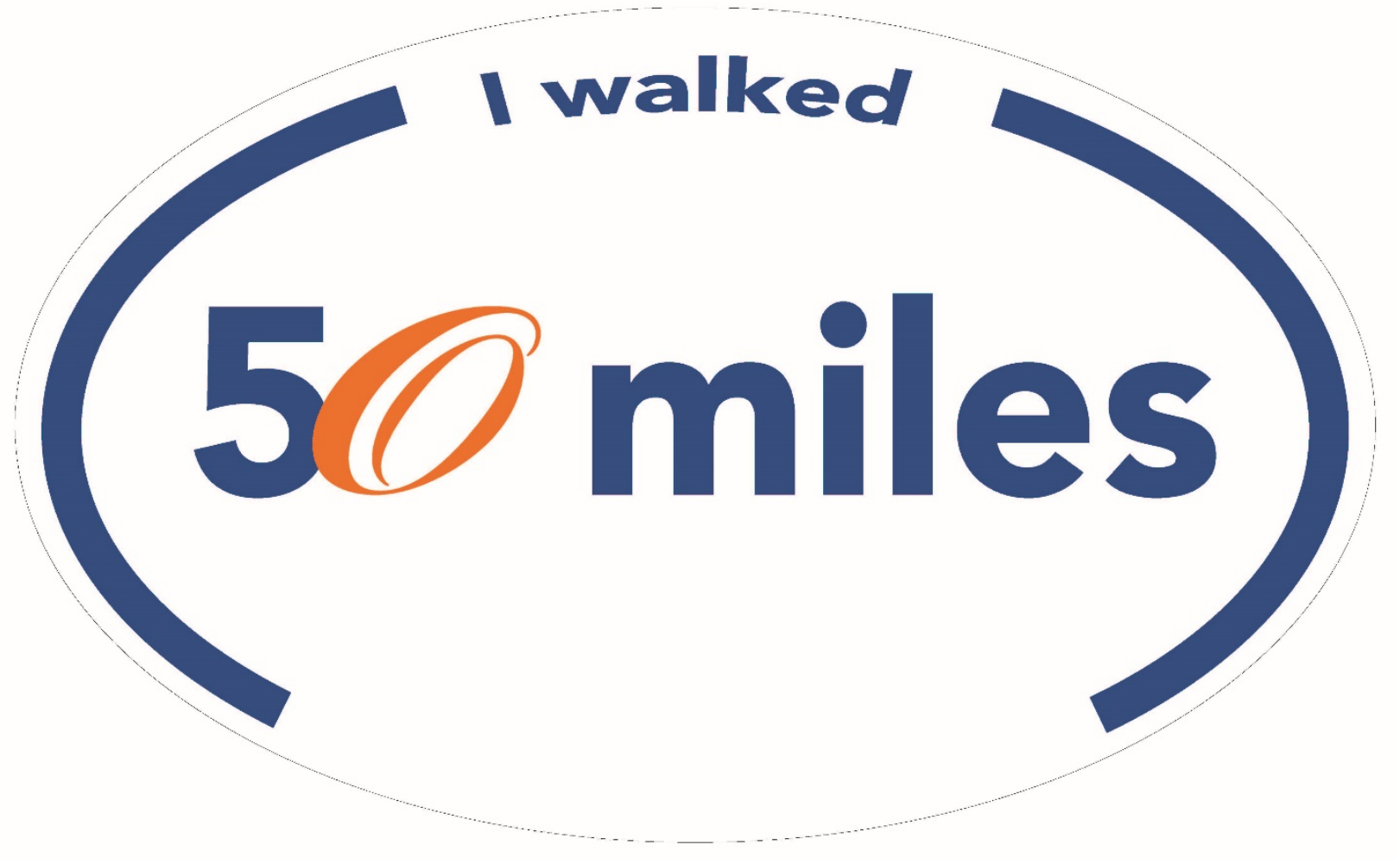




\section{Appendix G}

Email to Students

\section{Dear Student,}

Thank you for your interest in participating in the Suburban WALKS program! By filling out the information on the Google sheet to be shared with you, you indicate that you have read this email and are voluntarily participating in this walking program. You may stop at any time. The demographic questions at the top of the sheet are for statistical purposes only. None of your information will be shared.

Walking has many health benefits and is fun! If you have any concern about walking, please consult your doctor.

There will be recognition and motivation for you to keep walking. Anyone who continues to walk until November 1, 2019 will be entered in a drawing to receive a $\$ 100$ Amazon gift card. Walkers who reach 10,25, or 50 miles should emailwalk@sunyorange.edu to let me know of this accomplishment, and they will have their name posted on a large banner in the middle of each campus. Finally, anyone who reaches 50 miles (it CAN be done!) will receive a bumper sticker that says "I walked 50 miles at Suburban Community College."

The rules are simple: anytime you walk, preferably on or around campus, simply keep track of the number of minutes you walked, the number of people you spoke with, and whether you walked on or off campus. Enter this information for each day you walk on the Google sheet. The graph on your sheet will automatically track your progress. Note that for consistency, 20 minutes of walking will count as one mile. If you have an app or other step-counting device, please use it for your own information. For this walking program, please enter the number of minutes walked.

If you have any questions, please email me at walk@suburban.edu. Happy walking!

Sincerely,

Mrs. Prial 


\section{Appendix $\mathbf{H}$}

Old Dominion University Human Subject Approval Letter

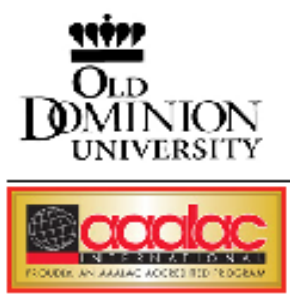

OFFICE OF THE VICE PRESIDENT FOR RESEARCH

4111 Monarch Wal Sutte 203 Nortolk, Virginla 23508

Malling Address

1 Old Dominion University

Nortolk, Virginla 23529

Phone(757) $683-3460$

Fax(757) 683-5902

DATE:

August 23, 2019

TO:

Mitchell Williams

FROM:

Old Dominion University Education Human Subjects Review Committee

PROJECT TITLE:

[1480046-1] The Impact of Moderate Physical Activity and Student

REFERENCE \#: Engagement on Retention at a Community College

SUBMISSION TYPE

New Project

ACTION:

DETERMINATION OF EXEMPT STATUS

DECISION DATE

August 23, 2019

REVIEW CATEGORY:

Exemption category \# 1

Thank you for your submission of New Project materials for this project. The Old Dominion University Education Human Subjects Review Committee has determined this project is EXEMPT FROM IRB REVIEW according to federal regulations.

We will retain a copy of this correspondence within our records.

If you have any questions, please contact Laura Chezan at (757) 683-7055 or Ichezan@odu.edu. Please include your project title and reference number in all correspondence with this committee.

This letter has been electronically signed in accordanoe with all appl cat University Education Human Subjects Review Committee's records. 


\section{Appendix I}

\section{Suburban Community College Human Subject Approval Letter}

August 26, 2019

To: Anne Prial

RE: IRB Application for human research titled: The Impact of Moderate Physical Exercise and Student Engagement on Retention at a Community College

Dear Ms. Prial,

This letter is to confirm that the [Suburban Community College] IRB has approved your application for this human study under the DHHS (OHRP) designation 45 CFR 46, effective August 26, 2019, pending your signature on the IRB application.

Please refer to the [Suburban CC] IRB application signature page for the list of responsibilities of the principal investigator. By signing this document, you agree to adhere to the principles set forth by the SUNY Orange IRB, and the DHHS. Please sign this page and return to me.

The submission of your periodic study review, using the Periodic Review and Continuing Research Form, will be due no later than August 26, 2020, unless the study is completed at an earlier date. If your study is completed prior to August 26, 2010, a periodic review will be due at the time of your study completion.

If you have any questions, please email me at christinework@[suburbancc].edu

Good luck with your research,

Sincerely,

Christine Work

Christine Work

Chair, [Suburban CC] IRB 
VITA

Anne Prial

Academic Profile

- PhD candidate, Old Dominion University, Norfolk, Va.

$09 / 16$ - present

- Attained 15 grad credits in Comm College Admin, Lenoir-Rhyne U. 05/14 - 12/15

- MA Applied Mathematics, Hofstra University, Hempstead, NY 09/85 - 05/88

- BS Mathematics, Manhattan College, Riverdale, NY

$09 / 83-05 / 85$

- AS Mathematics, Nassau Community College, Garden City, NY

$09 / 81-05 / 83$

\section{Awards/Honors}

- Graduated summa cum laude from Hofstra University

- Graduated summa cum laude from Manhattan College; won the Education Department Award

\section{Professional Experience}

Orange County Community College

Associate Vice President for Business, Math, Science, \& Technology Division

$8 / 15-$ present

- Supervise Department Chairs in Business, Mathematics, Biology, Science-Engineering-

Architecture, and Computer Science \& Technology Departments

- Oversee planning and budgeting across division

- Oversee curriculum development, programmatic reviews and course scheduling across division

- Coordinate faculty hiring

- Support internal and external community outreach

- Serve as an active member of the President's Cabinet

- Chair the college-wide Student Learning Assessment Team

- Serve on several search committees, including chairing search for Vice President of Academic Affairs

Orange County Community College, Department of Mathematics $\quad 8 / 12-8 / 15$ Department Chair

- Oversee 16 full-time and 50 part-time faculty members, as well as 2 staff members

- Responsible for all promotion, retention, and tenure applications in the Department

- Responsible for all departmental hiring, scheduling, and reports

\section{Conference Presentations}

- Say YES to Assess! Middle States Commission on Higher Education annual conference, $11 / 19 / 15$

- An Interactive Application of Discrete Mathematics, New York State Association of Two-Year Colleges annual conference, 4/19/13

\section{Professional Affiliations}

- New York State Mathematics Association of Two-Year Colleges

- National Council of Instructional Administrators 